Florida International University

FIU Digital Commons

3-27-2019

\title{
The Mediating Effects of Problematic Internet and Video Gaming Behaviors on Family, Cultural, and Individual Constructs among Latinx and non-Latinx Black Youth
}

Stephanie L. Diez

sdiez002@fiu.edu

Follow this and additional works at: https://digitalcommons.fiu.edu/etd

Part of the Social Work Commons

\section{Recommended Citation}

Diez, Stephanie L., "The Mediating Effects of Problematic Internet and Video Gaming Behaviors on Family, Cultural, and Individual Constructs among Latinx and non-Latinx Black Youth" (2019). FIU Electronic Theses and Dissertations. 3966.

https://digitalcommons.fiu.edu/etd/3966

This work is brought to you for free and open access by the University Graduate School at FIU Digital Commons. It has been accepted for inclusion in FIU Electronic Theses and Dissertations by an authorized administrator of FIU Digital Commons. For more information, please contact dcc@fiu.edu. 


\title{
FLORIDA INTERNATIONAL UNIVERSITY
}

Miami, Florida

\section{THE MEDIATING EFFECTS OF PROBLEMATIC INTERNET AND VIDEO GAMING BEHAVIORS ON FAMILY, CULTURAL, AND INDIVIDUAL CONSTRUCTS AMONG LATINX AND NON-LATINX BLACK YOUTH}

\author{
A dissertation submitted in partial fulfillment of \\ the requirements for the degree of \\ DOCTOR OF PHILOSOPHY \\ in \\ SOCIAL WELFARE \\ by \\ Stephanie L. Diez
}


To: Dean Tomás R. Guilarte

Robert Stempel College of Public Health and Social Work

This dissertation, written by Stephanie L. Diez, and entitled The Mediating Effects of Problematic Internet and Video Gaming Behaviors on Family, Cultural, and Individual Constructs among Latinx and non-Latinx Black Youth, having been approved in respect to style and intellectual content, is referred to you for judgment.

We have read this dissertation and recommend that it be approved.

$\begin{array}{r}\text { Nicole Fava } \\ \hline \text { Hui Huang } \\ \hline \text { Maureen Kenny } \\ \hline \text { Mario De La Rosa, Major Professor }\end{array}$

Date of Defense: March 27, 2019

The dissertation of Stephanie L. Diez is approved.

Dean Tomás R. Guilarte Robert Stempel College of Public Health and Social Work

Andrés G. Gil Vice President for Research and Economic Development and Dean of the University Graduate School

Florida International University, 2019 
(C) Copyright 2019 by Stephanie L. Diez

All rights reserved. 


\section{DEDICATION}

To my family. To my loving mother, Adriana Diez, for her encouragement and constant love that have sustained me throughout my life. To my sisters, Tatiana and Ivana, who have been endlessly caring throughout this process. In loving memory of my father, Hugo Diez, whose work ethic and tenacity I have inherited. Most of all, I dedicate this work to my partner, Javian Morel, to whom I am eternally grateful for his everlasting support during this journey. 


\section{ACKNOWLEDGMENTS}

I wish to express my deepest gratitude to my dissertation committee for all their continued support of my academic endeavors. Each dissertation committee member has provided me with professional and personal guidance that has shaped my perspective as a researcher, social worker, and academic. I am especially indebted to Dr. Mario De La Rosa, my dissertation chair and mentor, who has been supportive of my career goals and has provided me with ample opportunities to learn the skills necessary to pursue those goals. His words were always encouraging even during difficult times in the program. Additionally, I am grateful for all the tutelage I received from the many professors and researchers with whom I have had the pleasure to work with.

This work would not have been possible without the financial support of the CSALUD Student Scholar in Health Disparities Research Fellowship offered through the Center for Research on US Latino HIV/AIDS and Drug Abuse (CRUSADA) or the Dissertation Year Fellowship. 


\begin{abstract}
OF THE DISSERTATION
THE MEDIATING EFFECTS OF PROBLEMATIC INTERNET AND VIDEO

GAMING BEHAVIORS ON FAMILY, CULTURAL, AND INDIVIDUAL

CONSTRUCTS AMONG LATINX AND NON-LATINX BLACK YOUTH
\end{abstract}

by

Stephanie L. Diez

Florida International University, 2019

Miami, Florida

Professor Mario De La Rosa, Major Professor

Problematic Internet use (PIU) and problematic video gaming (PVG) are associated with various negative health outcomes and are increasingly concerning behavioral health issues among youth. While market research indicates that US Latinx use the Internet and video games more frequently than non-Latinx US youth, research on PIU and PVG among this historically understudied population is lacking. Accordingly, data on PIU, PVG, parental monitoring, sleep quality, substance use, anxiety, depression, parental attachment, acculturation, and positive future orientation were collected using validated standardized measures from three separate samples of US Latinx and nonLatinx youth.

The aims of this research were to explore the associations between PIU, PVG, and family, cultural, and individual wellbeing outcomes in a community sample of US Latinx and non-Latinx black adolescents. The first study $(N=159)$ examined the incidence of PVG among youth and found that younger elementary school aged males (ages 6-11) had 
the highest PVG scores, followed by middle school aged males (ages 12-14), and high school aged males (ages 15-18).

Building off previous research, the second study collected data $(N=247)$ examined PIU as a mediator of the association between parental monitoring and academic achievement, sleep quality, substance use, anxiety, and depression. Structural equation modelling (SEM) was used to estimate the relationships between the variables, controlling for adolescent's age, sex, and race/ethnicity. Results revealed that PIU is a significant mediator between parental monitoring and low academic achievement, sleep quality, substance use, anxiety, and depression.

A third study was conducted to examine if PIU and PVG mediate the relation between family, cultural, individual constructs and academic achievement. Two separate simple mediation models were tested using PROCESS ${ }^{\odot}$ macro v3.0 for SPSS 25. Results from the hypothesized mediation models were not significant. Suggestions for future research to examine critical Latinx cultural values and their influence on behavioral health is discussed. 


\section{TABLE OF CONTENTS}

CHAPTER

PAGE

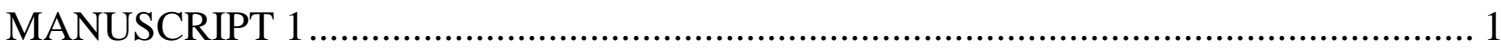

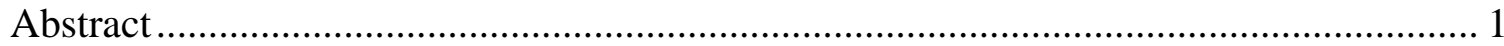

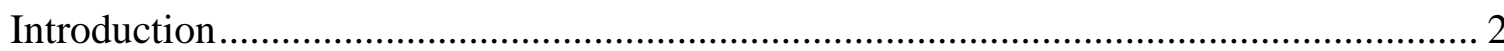

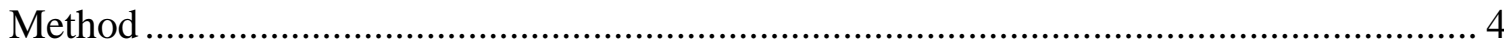

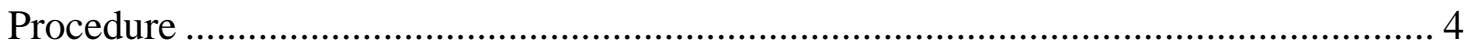

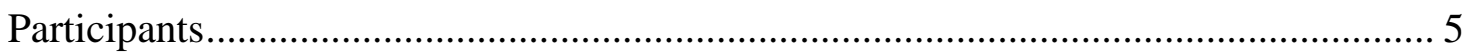

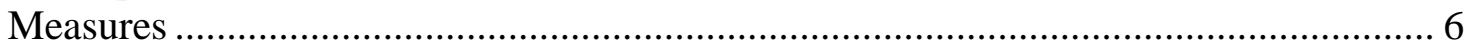

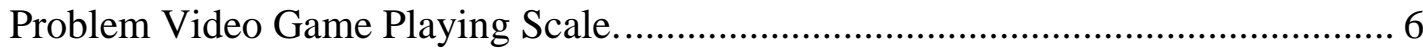

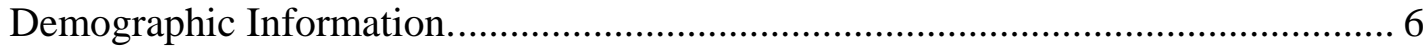

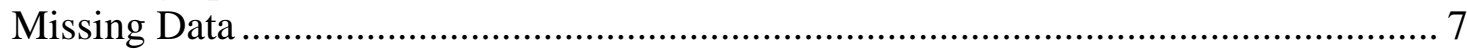

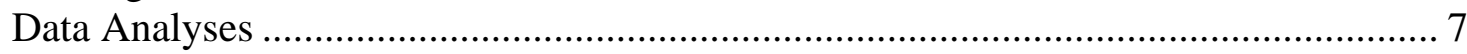

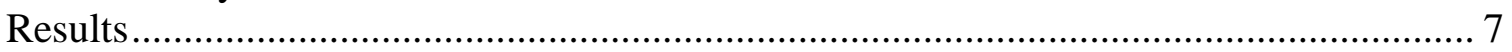

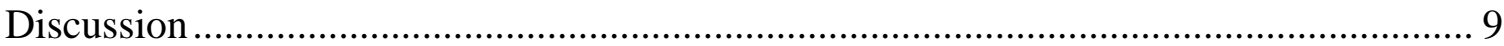

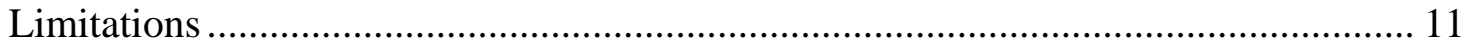

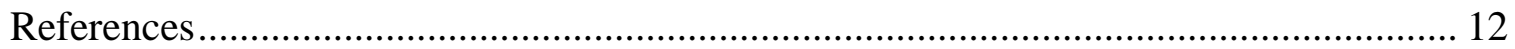

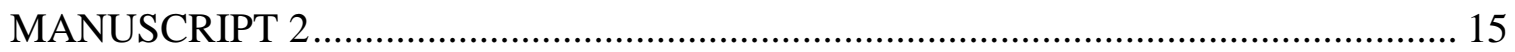

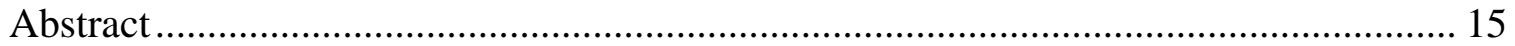

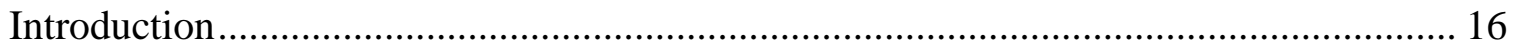

Problematic Internet Use (PIU) ......................................................................... 17

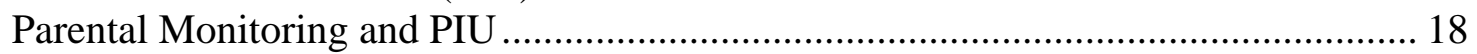

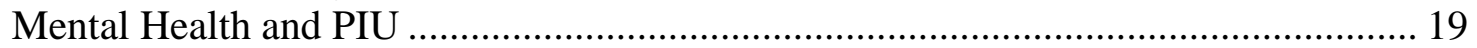

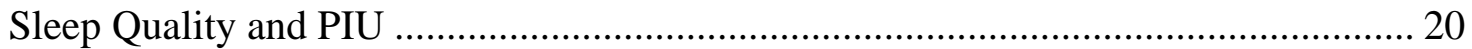

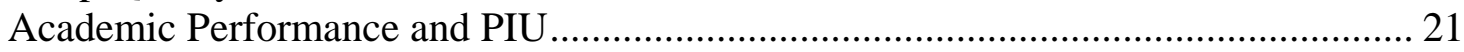

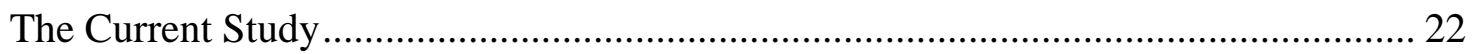

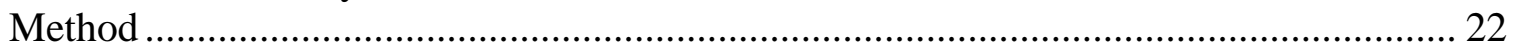

Procedure ……

Sample

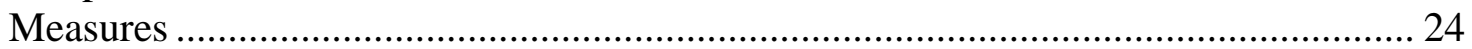

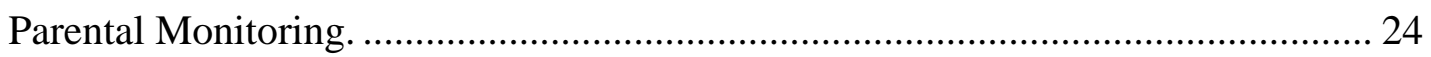

Problematic Internet Use................................................................................ 24

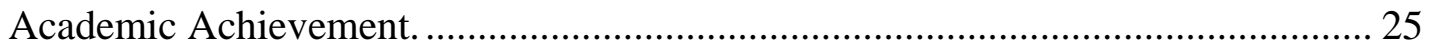

Substance use and mental health...................................................................... 25

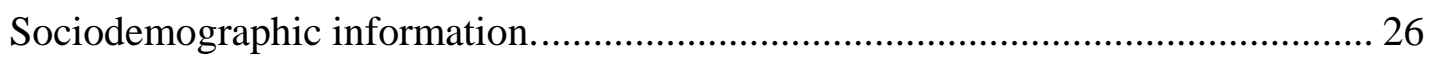

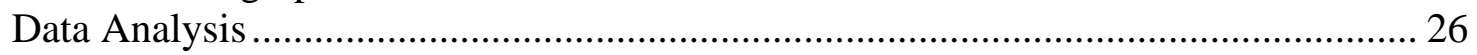

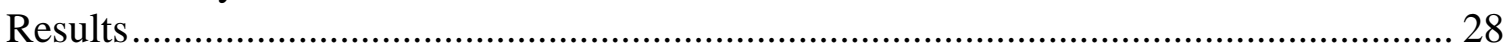

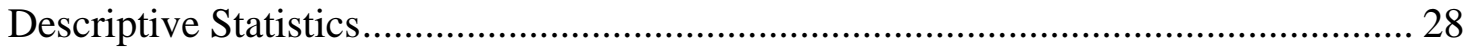

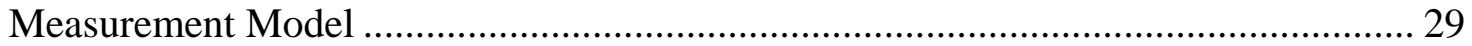

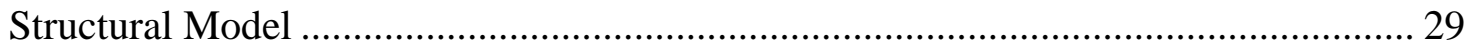

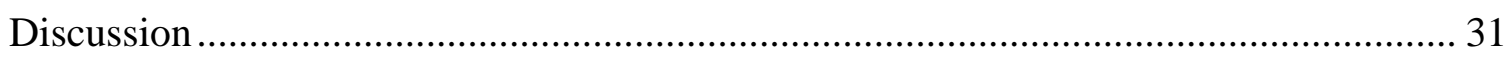

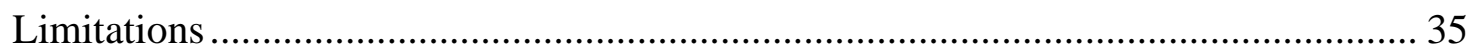

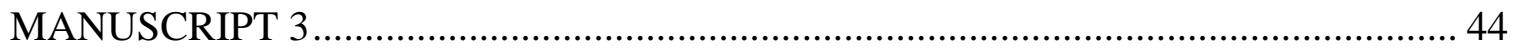




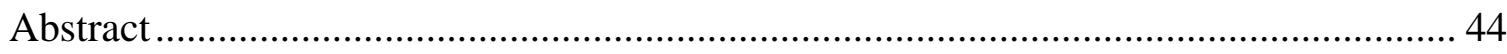

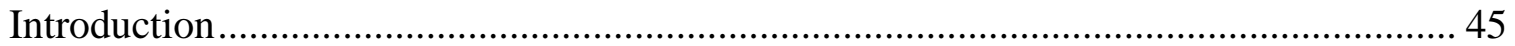

Family Household Composition and PIU/PVG .................................................... 47

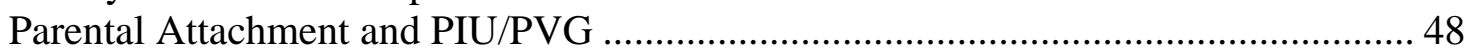

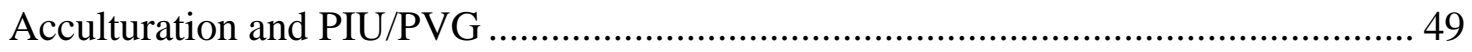

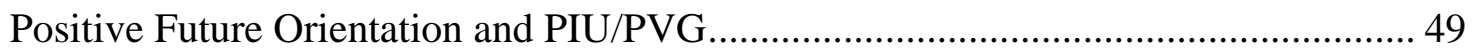

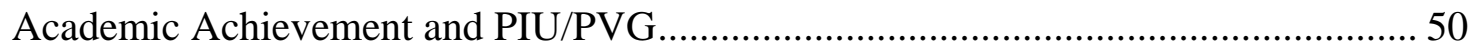

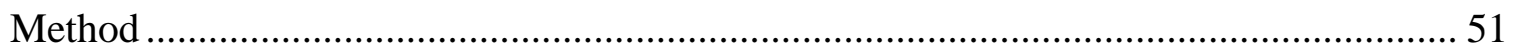

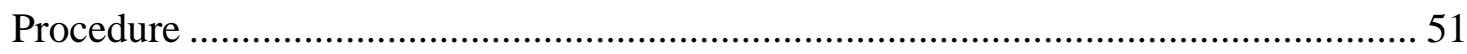

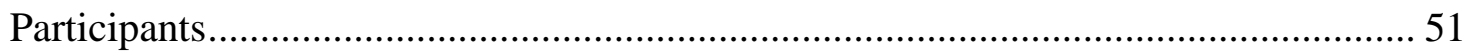

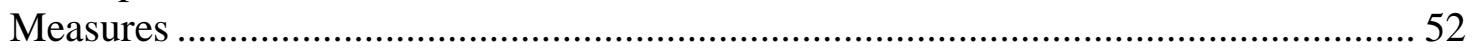

Problematic Internet Use Questionnaire. .............................................................. 52

Problem Video Game Playing Scale.................................................................. 52

Family Household Composition. ............................................................................ 53

Inventory of Parent and Peer Attachment (IPPA) .................................................. 53

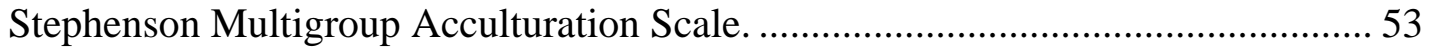

Adolescent Resilience Scale: Positive Future Orientation......................................... 54

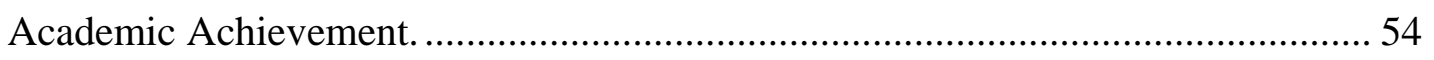

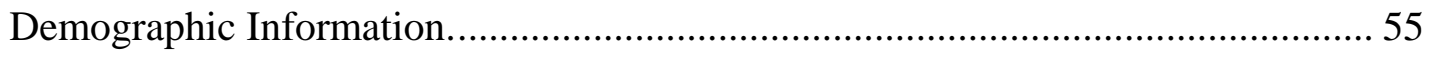

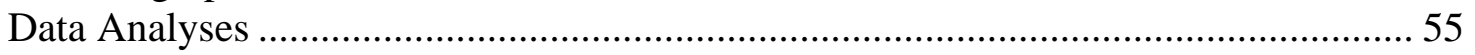

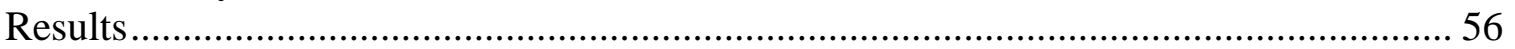

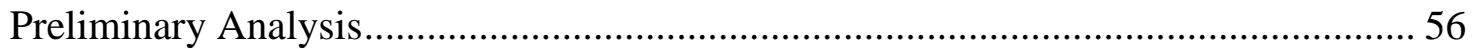

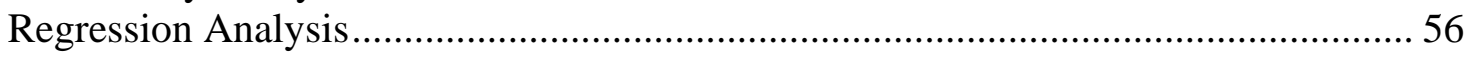

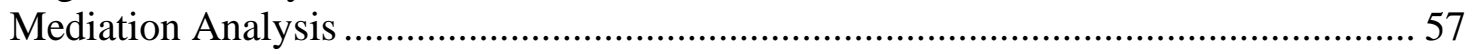

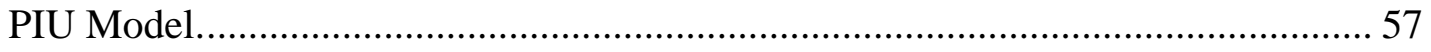

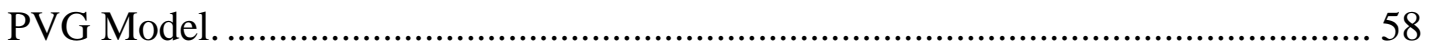

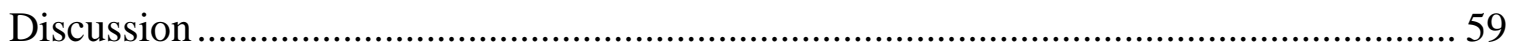

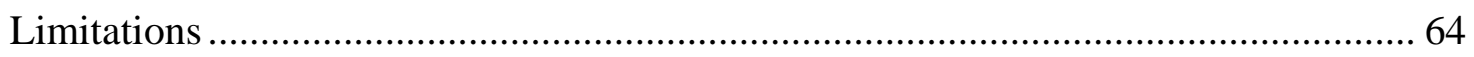

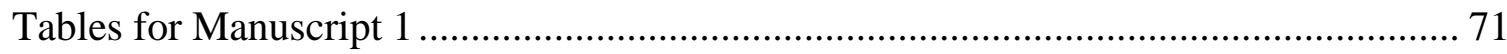

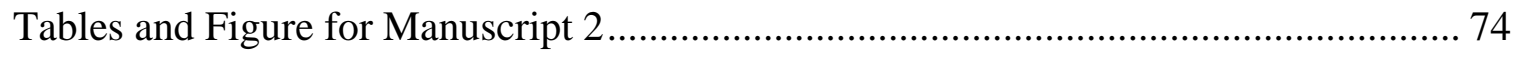

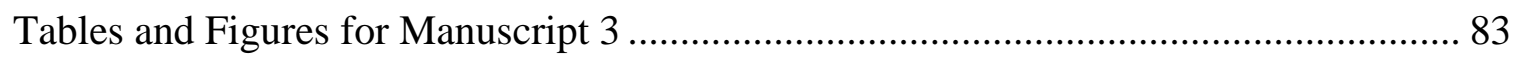

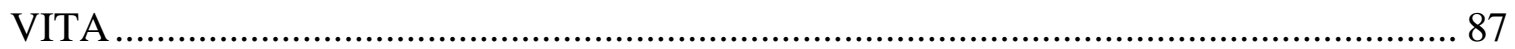




\title{
MANUSCRIPT 1
}

\begin{abstract}
As media reports increasing numbers of youth in the United States are playing video games, the potential of developing a behavioral addiction escalates. The potential effects of problematic video game playing (PVG) that may lead to Internet Gaming Disorder should be considered. The aim of this study was to explore the occurrence of PVG by gender and age-related aspects in a community sample of U.S. children. The sample consisted of 159 youth, mean age of participants was $12.6(\mathrm{SD}=3.2)$, with nearly half being of elementary school age $(48.0 \%, n=76)$. Participants completed the 9-item unidimensional Problem Video Game Playing Scale that examines eight dimensions of addiction. A two-way factorial ANOVA was conducted to examine interaction effects between sex and age. The dimension of addiction with the highest endorsement was loss of control. Findings indicated main effects for sex. Younger elementary school aged males (ages 6-11) had the highest PVG scores. Future research is needed to determine if problematic video gaming behaviors track into adulthood.

Keywords: Problematic video gaming, Internet Gaming Disorder, youth, children
\end{abstract}


Problematic Video Gaming Among Youth: An Empirical Examination

\section{Introduction}

Video game use is prevalent among youth in part due to advancements in the Internet and its related technologies that have contributed to obtainability of video game playing among youth (Lenhart, Kahne, Middaugh, Macgil, Evans, \& Vitak, 2014; Lenhart, 2015). As a response, research has developed related to how video game playing may negatively impact youth (Hull, Williams, \& Griffiths, 2013). Problematic video gaming (PVG), also defined as Internet gaming disorder (IGD), are central concepts in the growing body of research focusing on the adverse effects of excessive video game use that can lead to addiction (Griffiths, Kuss, \& King, 2012; Griffiths \& Meredith, 2009; Young, 2009). Although the debate over the operational definition of PVG/IGD continues (Blaszczynski, 2008; Griffiths, King, \& Demetrovics, 2014; Turner, 2008; Wood, 2008a, 2008b), it has been categorized as a behavioral addiction in which an individual loses control to excessive or compulsive video game use despite negative consequences (Grant, Potenza, Weinstein, \& Gorelick, 2010). The behavioral addiction of PVG/IGD entails dimensions of addiction inclusing preoccupation, withdrawal, tolerance, and loss of control (Griffiths \& Dancaster 1995; Griffiths \& Hunt 1998; Johansson \& Go“testam, 2004).

In 2013, the American Psychiatric Association recognized IGD to be considered as a formal disorder in the Diagnostic and Statistical Manual of Mental Disorders 5 (DSM5), and requested further research be conducted [American Psychiatric Association (APA, 2013, p. 795-798; 2013b]. Most recently, the World Health Organization (WHO) included IGD in the International Classification of Diseases (ICD-11) as a formal 
disorder. Both the APA and WHO define IGD as a pattern of "video-gaming behavior characterized by impaired control over gaming to the extent that gaming takes precedence over all other interests and daily activities, to the point of continuation or escalation of gaming despite the occurrence of negative consequences" (APA, 2013, p. 795-798; WHO, 2018).

Video games continue to evolve and play a pivotal role in the lives of youth as $97 \%$ of U.S. adolescents (ages 12-17) report video game use via web, portable, or console devices (Lenhart et al., 2014). It is imperative to detect potential problematic behaviors early to reduce the risk of addiction. Similar to drug and alcohol addictions, one of the first warning signs of IGD is isolation from family and social events (Young, 2009). Additionally, the majority of research on IGD has examined populations of youth and young adults in Asian and European countries (King, Delfabbro, Griffiths, \& Gradisar, 2011), despite the popularity of video game use among U.S. youth. Across different samples and approaches to measurement, somewhere between $3 \%$ and $10 \%$ of adolescents are impacted by symptoms of IGD that parallel those experienced by people with substance use disorders (Kuss, Griffiths, \& Pontes, 2016). These symptoms include dimensions of preoccupation, tolerance, withdrawal, loss of control, and negative consequences as a result of the problematic video gaming (Festl, Scharkow, \& Quandt, 2013; Kuss, Griffiths, and Pontes, 2016; Rehbein, Kliem, Baier, Mößle, \& Petry, 2015). Previous research has focused on differing vulnerabilities to problem video game use by sex and age (Kuss \& Griffiths 2012a, 2012b; Lucas \& Sherry, 2004; Sim, Gentile, Bricolo, Serpelloni, \& Gulamoydeen, 2012). Evidence has supported that males are more likely to self-identify as having IGD (Desai, Krishnan-Sarin, Cavallo, \& Potenza, 2010) 
and score higher on a measure of IGD than high school aged females (Salguero \& Morán, 2002). Correspondingly, in a nationally representative sample, U.S. adult males had higher IGD scores than adult females (Elliott, Ream, McGinsky, \& Dunlap, 2012). Continued research and discussion are needed on IGD among varying samples, due to the complex nature of problematic video game usage and the integration of the Internet as a global venue for video game playing worldwide (Gentile, 2009; Griffiths, Kuss, \& King, 2012; Kuss \& Griffiths, 2012a, 2012b; Salguero, \& Morán, 2002).

To examine the knowledge deficit in prevelance of PVG among elementary school aged children in the literature, the current study examined PVG among elementary, middle, and high school aged youth. The primary aim of the current study was to examine interactions between sex and age by school grade range and PVG levels among U.S. youth. Thus addressing a gap in the literature and providing a window into some of the factors that may be influencing PVG in a sample of elementary, middle, and high school aged youth in the U.S. Additionally, the current study responds to the APA's request for additional research on these developing pathological behaviors (APA, 2013). The current study hypothesized that high school aged males will have higher Problem Video Game Playing scores than females.

\section{Method}

\section{Procedure}

Participants were recruited from health fairs in schools and community centers throughout Broward and Miami-Dade counties_-located in Southeast Florida. All the youth who attended the events were invited to participate in the study. Each participant completed a paper and pencil survey individually, and for quality control a trained 
volunteer from the nonprofit organization observed the participant and was available to answer questions.

Prior to beginning the survey, participants read and reviewed the assent form and were provided with comprehensive information about the study. Informed consent was obtained from parents or legal guardians for all participants under 18 years old. For those who were 18 years and older, a paper consent was obtained from them. Approval from the Institutional Review Board to which the researchers are affiliated was obtained.

Inclusion criteria for this study were being able to independently read and write, being between the ages of 6-18 years old, and having played video games within the past 6 months. Upon meeting inclusion criteria, the participants' guardians provided verbal consent while participants provided verbal assent and were advised of their right to withdraw their participation at any time during the study. Participants were offered a snack in exchange for completing a questionnaire; some accepted the snack while others declined.

\section{Participants}

The current sample consisted of youth $(M=12.6$ years old, $S D=3.2$, range $=6$ 18 years old) just over half $(51.2 \% ; n=82)$ of the participants were female. The mean age of participants was 12.6 years $(\mathrm{SD}=3.2)$, with nearly half $(n=76,48.0 \%)$ being of elementary school age (6-11 years old), followed by those in the high school (15-18 years old; $n=45 ; 28.3 \%)$ and middle school (12-14 years old; $n=38,23.7 \%)$ age ranges. Participants resided in 20 cities located within in two metropolitan counties, with the majority (72.7\%) residing in Broward County. 


\section{Measures}

Problem Video Game Playing Scale. The Problem Video Game Playing scale was used to measure problematic video gaming among participants. Designed by Salguero and Morán (2002), the nine-item dichotomous response questionnaire was developed to measure the level of dependence on video game play. Participants were asked questions in the form of a statement with a dichotomous response $(0=$ No, $1=$ Yes) regarding their video game usage such as "When I feel bad (i.e., nervous, sad, or angry) or when I have problems, I use video games more often", "In order to play video games I have skipped classes or work, lied or stolen, or had an argument or a fight with someone," and "Sometimes I conceal my video game playing to others, this is my parents, friends, or teachers". The scale can be summed from 0-9, with a higher score indicating more problematic video game playing; no cut-off point was proposed for the Problem Video Game Playing scale (Salguero \& Morán, 2002). The scale is unidimensional and measures the following eight dimensions of addiction: preoccupation (item 1), tolerance (item 2), loss of control (item 3, item 6), withdrawal (item 4), escape (item 5), lies and deception (item 7), disregard for the physical or psychological consequences (item 8), and family/school disruption (item 9).

Demographic Information. Participants' demographic information, including age, biological sex, city, and county of residence was self-reported by participants. Age ranges were grouped and recoded into three school age range variables: age 6-11 as Elementary School Age, age 12-14 as Middle School Age, age 15- 18 as High School Age. 


\section{Missing Data}

Missing data was minimal in the current study. One participant $(0.63 \%)$ did not complete the entire measure, leaving out five of the items, and was removed using listwise deletion.

\section{Data Analyses}

Preliminary data analyses to test for assumptions of normality, bivariate outliers and descriptive statistics were conducted using IBM Statistical Package for Social Science (SPSS) Statistics version 22.0 (IBM SPSS Corp, 2013). This includes examining the PVG score totals, means, and percentages. To test group differences, a factorial analysis of variance (ANOVA) using SPSS general linear modeling (GLM), with Levene's tests to determine homogeneity of variances across groups and with a $p<.05$ standard was used. Estimated effect sizes are reported based on the partial $\eta^{2}$ reported in the factorial ANOVA and interpreted using Cohen's (Cohen, 2013) designation of .010 (small), .059 (medium), and .138 (large) effect sizes.

\section{Results}

Preliminary data analyses were conducted to test for assumptions of normality and significant outliers. The overall measure was normally distributed (skewness $=.431$ $[\mathrm{SE}=.195]$ and kurtosis $=-.483[\mathrm{SE}=.387])$ and no outliers were found .

Descriptive statistics on the most frequently reported items of the scale was examined by dimension (see Table 1). The items with the highest endorsement sequentially were: item 6 loss of control, "When I lose in a game or I have not obtained the desired results, I need to play again to achieve my target" $(56.3 \%, n=90)$, item 3 loss of control, "I have tried to control, cut back, stop playing, and I usually play video games 
over a longer period of time than I intended" $(49.7 \%, n=79)$, item 1 preoccupation, "When I am not playing with video games, I keep thinking about them (i.e. remembering games, planning the next game, etc.)" $(40.0 \%, n=64)$, item 5 escape, "When I feel bad, (e.g. nervous, sad, or angry) or when I have problems, I use video games more often" $(36.1 \%, n=57)$, item 2 tolerance, "I spend an increasing amount of time playing video games" $(31.9 \%, n=51)$, item 7 lies and deception, "Sometime I conceal my video game playing to others like my parents, friends, teachers, etc." $(31.6 \%, n=50)$, item 4 withdrawal, "When I can't use video games I get restless or irritable" $(26.4 \%, n=42)$, item 9 family/schooling disruption, "Because of video game playing I have spent less time on my homework, schoolwork, or I have not eaten, I have gone to bed late, or I spent less time with my friends and family" $(25.0 \%, n=40)$. The remaining item, item 8 disregard for physical or psychological consequences, "In order to play video games I have skipped classes or work, lied, stolen, or had an argument or fight with someone, was reported by less than ten percent $(9.4 \%, n=15)$ of the sample.

Problem Video Game Playing scores across the total sample $(N=159)$ had a mean score of $3.07(\mathrm{SD}=2.12$; see Table 2$)$. Males had overall higher mean scores ranging from 2.00- 4.47, while female mean scores ranged from 2.04-2.67. Problem Video Game Playing scores were examined across school age ranges with elementary school aged youth reporting the highest mean scores $(3.57, \mathrm{SD}=2.13)$, followed by middle school aged youth $(3.16, \mathrm{SD}=2.21)$, and high school aged youth had the lowest PVG score $(2.02, \mathrm{SD}=1.44)$. There was a statistically significant difference between the mean scale scores of high school ages participants, middle school, and elementary, 
however no significant mean score differences were observed between the elementary and middle school aged youth.

The Levene's test of equality of variances for the two-way factorial ANOVA were not significant, $F(5,153)=1.51, p=.19$, indicating homogeneity of variances. The ANOVA results, presented in Table 3, show a significant main effect for sex, $F(1,153)=$

$8.35, p=.004$, partial $\eta^{2}=.052$, as a medium effect size. Males had a significantly higher mean score $(M=3.62, S D=2.11)$ than females $(M=2.47, S D=1.89)$. There was also a significant main effect for school age level, $F(2,153)=9.54, p<.001$, partial $\eta^{2}=.111$, close to a large effect size. A Scheffé post hoc test was conducted to determine which school age levels were significantly different.

There was a significant interaction effect between sex and age, $F(2,24.43)=$ $32.45, p=.03$, partial $\eta^{2}=.043$, close to a medium effect size, as shown in Table 3 . To examine statistical differences within sex across age groups, separate factorial ANOVAs were completed. There were no significant differences between school age groups among females in this sample, $F(2,78)=.93, p=.40$. However, there was a significant difference across age groups for males, $F(2,75)=11.47, p<.001$, partial $\eta^{2}=.234$, a large effect size. Scheffé post hoc tests indicated significant differences between elementary school aged males' Problem Video Game Playing scale scores and high school aged males' mean scores $(p<.001)$ and between middle school aged and high school aged males $(p=.02)$.

\section{Discussion}

Research on IGD has primarily focused on varying international samples comprised of adolescent and adult participants. For nearly two decades, empirical studies 
and media reports indicate children engage in excessive video gaming behaviors associated with pathological symptoms (Salguero and Morán, 2002). Yet the prevalence of IGD among children has yet to be widely examined. Due to a dearth of empirical evidence for IGD among children in the U.S., and pertinent to the increase in video gaming among youth, the current study examined PVG in a community sample of U.S. children. Accordingly, the aim of this study was to explore the occurrence of PVG and to examine interactions between sex and age by PVG levels among U.S. children.

Overall, results indicated elementary school aged males (ages 6-11) had the highest PVG scores among the participants in this study. Our findings contribute to the discussion that advancement in video game platforms/technologies may promote and escalate video game playing behaviors and thereby elevate the risk of problematic video gaming among this age group of boys. Although playing video games is a form of recreational activity, young children who use video games may be most susceptible to PVG, which has the potential to develop into IGD. A longitudinal study of Korean adolescents into adulthood examined levels of PVG using latent class analysis and found that males were more likely to belong to a chronic group of PVG users who maintained a high level of video game addiction and total hours played (Hong, You, Kim, \& No, 2014). Data from the U.S. National Longitudinal Study of Adolescent Health (Add Health) assessed hours of video game and television use as 'screen time' among youth and found that excessive screen time tracked into adulthood (Gordon-Larsen, Nelson, \& Popkin, 2004). Therefore, it is crucial to identify and intervene with children exhibiting PVG behaviors during this developmental period as they may continue into adulthood (Coffey, Carlin, Lynskey, Li, \& Patton, 2003). 
Similar findings from previous studies also indicate that adolescent males are more likely than females to have a higher PVP score (Desai et al., 2010; Elliott et al., 2012; Salguero \& Morán, 2002). While elementary school aged males in the current study were found to exhibit problematic video gaming at higher levels then other school aged males, Salguero and Morán's (2002) PVP scale mean scores differed considerably. Salguero and Morán's (2002) mean scores for Spanish male youth ranged from 2.662.83. The mean scores for Spanish female youth ranged from 1.37-1.61 (Salguero \& Morán, 2002), which is less than the current study scores. In the present study, differences in mean scores are greater with males scores varying from 2.70-3.62 and females scores ranging from 1.50-2.47.

Previous literature has focused on PVG/IGD among high school aged youth and few studies have compared PVG scores of elementary school aged youth to older youth. This study provides evidence that additional research is needed to more comprehensively understand the underlying factors associated with PVG/IGD among elementary school aged children. Results from the most frequently endorsed items (i.e. loss of control,), have important implications for clinicians to target young males for the prevention of problematic behaviors before it develops into IGD. Future research should longitudinally examine this emergent issue and identify psychosocial factors attributing to PVG among U.S. children.

\section{Limitations}

Although the current study makes a significant contribution to the literature, there are several limitations including a non-random sample, self-reported data, and limited demographic information. It is important for future studies examining PVG to consider 
the sample's demographic information. In addition, the PVG Scale does not include a defined threshold to indicate a cut-off point for addiction. Future, empirical data-driven evidence should be gathered on children's PVG/IGD usage to assess problematic traits associated with usage, and better understand how to assess and prevent this behavioral addiction.

\section{References}

American Psychiatric Association (APA) (2013). Diagnostic and Statistical Manual of Mental Disorders, 5th ed. Washington, DC; London, England: American Psychiatric Association.

Blaszczynski, A. (2008) Commentary: a response to 'Problems with the Concept of Video Game “Addiction”: Some Case Study Examples'. International Journal of Mental Health and Addiction, 6, 179-181.

Coffey, C., Carlin, J. B., Lynskey, M., Li, N., \& Patton, G. C. (2003). Adolescent precursors of cannabis dependence: findings from the Victorian Adolescent Health Cohort Study. The British Journal of Psychiatry, 182(4), 330-336.

Cohen, J. (2013). Statistical power analysis for the behavioral sciences. Routledge.

Corp, I. B. M. (2013). IBM SPSS statistics for windows, version 22.0. Armonk, NY: IBM Corp.

Desai, R. A., Krishnan-Sarin, S., Cavallo, D., \& Potenza, M. N. (2010). Video-gaming among high school students: Health correlates, gender differences, and problematic gaming. Pediatrics (Evanston), 126(6), e1414-e1424. doi: http://dx.doi.org/10.1542/peds.2009-2706

Elliott, L., Ream, G., McGinsky, E., \& Dunlap, E. (2012). The contribution of game genre and other use patterns to problem video game play among adult video gamers. International Journal of Mental Health and Addiction, 10(6), 948-969.

Gentile, D. (2009). Pathological video-game use among youth ages 8 to 18: a national study. Psychological Science, 20(5), 594-602.

Gordon-Larsen, P., Nelson, M. C., \& Popkin, B. M. (2004). Longitudinal physical activity and sedentary behavior trends: adolescence to adulthood. American journal of preventive medicine, 27(4), 277-283. 
Grant, J. E., Potenza, M. N., Weinstein, A., \& Gorelick, D. A. (2010). Introduction to Behavioral Addiction. American Journal of Drug Alcohol Abuse, 36(5), 233-241.

Griffiths, M. D., \& Dancaster, I. (1995). The effect of Type A personality on physiological arousal while playing computer games. Addictive Behaviors, 20, 543-548.

Griffiths, M. D., \& Hunt, N. (1998). Dependence on computer games by adolescents. Psychological Reports, 82, 475-480.

Griffiths, M., King, D., \& Demetrovics, Z. (2014). DSM-5 internet gaming disorder needs a unified approach to assessment. Neuropsychiatry, 4(1), 1-4.

Griffiths, M. D., Kuss, D.J., \& King, D. L. (2012). Video game addiction: Past, present and future. Current Psychiatry Reviews, 8, 308-318.

Griffiths, M. D., \& Meredith, A. (2009). Videogame addiction and its treatment. Journal of Contemporary Psychotherapy, 39(4), 247-253.

Hong, S., You, S., Kim, E., \& No, U. (2014). A group-based modeling approach to estimating longitudinal trajectories of korean adolescents' on-line game time. Personality and Individual Differences, 59, 9-15. doi:http://dx.doi.org.ezproxy.fiu.edu/10.1016/j.paid.2013.10.018

Hull, D. C., Williams, G. A., \& Griffiths, M. D. (2013) Video game characteristics, happiness and flow as predictors of addiction among video game players: A pilot study. Journal of Behavioral Addictions, 2(3), 145-152.

Johansson, A., \& Go“testam, K. G. (2004). Internet addiction: Characteristics of a questionnaire and prevalence in Norwegian youth. Scandinavian Journal of Psychology, 45, 223-229.

King, D. L., Delfabbro, P. H., Griffiths, M. D., \& Gradisar, M. (2011). Assessing clinical trials of Internet addiction treatment: a systematic review and CONSORT evaluation. Clinical Psychology Review, 31, 1110-1116.

Kuss, D. J., \& Griffiths, M. D. (2012a). Internet and gaming addiction: A systematic literature review of neuroimaging studies. Brain Sciences, 2(3), 347-374. doi: http://dx.doi.org/10.3390/brainsci2030347

Kuss, D. J., \& Griffiths, M. D. (2012b). Internet gaming addiction: A systematic review of empirical research. International Journal of Mental Health and Addiction, 10(2), 278-296. doi: http://dx.doi.org.ezproxy.fiu.edu/10.1007/s11469-011-93185 
Lenhart, A., Kahne, J., Middaugh, E. Macgil, A., Evans, C., \& Vitak, J. (2014). Teens, Video Games and Civics. Pew Research Center. Retrieved from: http://www.pewinternet.org/2008/09/16/teens-video-games-and-civics/

Lenhart, A. (2015). Teens, Social Media \& Technology Overview 2015. Pew Research Center. Retrieved from: http://www.pewinternet.org/2015/04/09/teens-socialmedia-technology-2015/

Lucas, K., \& Sherry, J. L. (2004). Sex differences in video game play: A communicationbased explanation. Communication Research, 31(5), 499-523. doi: http://dx.doi.org.ezproxy.fiu.edu/10.1177/0093650204267930

Rehbein, F., Kliem, S., Baier, D., Mößle, T., \& Petry, N. M. (2015). Prevalence of internet gaming disorder in German adolescents: diagnostic contribution of the nine DSM-5 criteria in a state-wide representative sample. Addiction, 110(5), 842851

Salguero, R.A.T., \& Morán, R.M.B. (2002). Measuring problem video game playing in adolescents. Society for the Study of Addiction to Alcohol and Other Drugs, 97(12), 1601-1606.

Sim, T., Gentile, D. A., Bricolo, F., Serpelloni, G., \& Gulamoydeen, F. (2012). A conceptual review of research on the pathological use of computers, video games, and the Internet. International Journal of Mental Health and Addiction, 10(5), 748-769. doi: http://dx.doi.org.ezproxy.fiu.edu/10.1007/s11469-011-9369-7

Turner, N. (2008) A Comment on "Problems With the Concept of Video Game 'Addiction': Some Case Study Examples”. International Journal of Mental Health and Addiction, 6, 186-190.

WORLD HEALTH ORGANIZATION. (2018). The ICD-11 classification of mental and behavioral disorders: clinical descriptions and diagnostic guidelines. Geneva, World Health Organization.

Wood, R. (2008a) Problems with the concept of video game 'addiction': some case study examples. International Journal of Mental Health and Addiction, 6, 169-178.

Wood, R. (2008b) A response to Blaszczynski, Griffiths and Turners'comments on the paper 'Problems with the Concept of Video Game "Addiction": Some Case Study Examples' (this issue). International Journal of Mental Health and Addiction, 6, 191-193.

Young, K. (2009). Understanding online gaming addiction and treatment issues for adolescents. The American Journal of Family Therapy, 37(5), 355-372. 


\title{
MANUSCRIPT 2
}

\begin{abstract}
Problematic Internet use (PIU) is an increasing behavioral health concern among youth and is associated with various negative outcomes. For nearly two decades researchers have explored PIU among adolescents, yet scant literature has investigated PIU among Latinx and non-Latinx Black adolescents despite their significant representation in the United States population. The current study examines PIU as a mediator of the association between parental monitoring and academic achievement, sleep quality, substance use, anxiety, and depression. Data were collected from 247 adolescents $(M$ age $=16.0, S D=1.2)$, wherein a majority were girls $(63.6 \%)$ and nonLatinx Black (69.2\%; Latinx (27.1\%). Structural equation modelling (SEM) was used to estimate the associations between the variables, controlling for adolescent's age, biological sex, and race/ethnicity. Results of SEM analyses revealed that PIU is a significant mediator between parental monitoring and low academic achievement, sleep quality, substance use, anxiety, and depression. These findings identify points of prevention, such as parental monitoring, that clinicians can utilize to prevent adolescents from developing PIU. Furthermore, this research highlights the need for longitudinal research with larger, representative samples to determine causality.
\end{abstract}


The Mediating Effect of Problematic Internet Use on the association between Parental Monitoring and Well-Being Outcomes among Latinx and non-Latinx Black Adolescents

\section{Introduction}

Internet use is nearly universal among adolescents in the United States (US); approximately $90 \%$ of US adolescents aged 13 to 17 access the Internet daily and $24 \%$ use the Internet almost constantly (Lenhart, 2015). Historically, Latinx and non-Latinx Black adolescents with lower socioeconomic status were less likely to access the Internet (Smith, 2014), however, in recent years, Internet access has greatly increased among US minority adolescents who have varied access to the Internet via school, recreation centers, work, or home with a myriad of technological devices (Smith, 2014). Although many adolescents may benefit from the Internet by accessing a broad range of information, the potential negative effects of problematic Internet use (PIU) should be considered (Anderson, Steen, \& Stavropoulos, 2017). Scant literature has investigated PIU among Latinx and non-Latinx Black adolescents despite their significant representation in the US population: 18.1\% (Latinx) and 13.1\% (non-Latinx Black; US Census, 2017). Several studies have reported that Latinx and non-Latinx Black adolescents engage in more frequent use of the Internet and may have a higher prevalence of PIU compared to their White peers (Carson, Cook, Chen, \& Alegria, 2012; Lenhart, 2015; Liu et al., 2011).

To date, there is scant literature on the effects of parental monitoring on PIU and other known negative outcomes (e.g., mental health, substance use, sleep quality, and academic achievement) among US Latinx and non-Latinx Black adolescents, as most studies have examined PIU primarily among international samples of youth. Given prior research on the protective effects of parental monitoring on health risk behaviors and 
Internet use behavior among varying samples of international adolescents and youth, this study proposes to explore the role of adolescents perceived parental monitoring and its effect on adolescent wellbeing. More specifically, this study will examine the associations between parental monitoring and addictive behaviors (i.e., substance use and PIU), mental health (i.e. sleep quality, depression, and anxiety), and school performance (i.e., GPA). Additionally, the current study will examine the influence of PIU as a mediator to the association between parental monitoring and academic achievement, sleep quality, substance use, anxiety, and depression among a sample of Latinx and nonLatinx Black adolescents.

\section{Problematic Internet Use (PIU)}

Excessive Internet use, or problematic Internet use (PIU), is defined as a behavioral addiction, with characteristics similar to a substance use disorder, categorized by a pathological pattern of excessive Internet use (Liu \& Potenza, 2007; Spada, 2014). The harmful consequences of PIU are particularly relevant to adolescents and include negative impacts on academic achievement (Gentile, Choo, Liau, Sim, Li, Fung, \& Khoo, 2011; Stavropoulos, Alexandraki, \& Motti-Stefanidi, 2013), symptoms of depression (Dong, Lu, Zhou, \& Zhao, 2011; Gentile et al., 2011; Kraut, Patterson, Lundmark, Kiesler, Mukophadhyay, \& Scherlis, 1998; Selfhout, Branje, Delsing, ter Bogt, \& Meeus, 2009), and comorbid symptoms including anxiety and psychopathology in general (Kuss, Griffiths, Karila, \& Billieux, 2014; Kuss \& Lopez-Fernandez, 2016).For nearly two decades, researchers have explored PIU among adolescents and young adults (e.g. Cheng \& Li, 2014; Kuss, Griffiths, Karila, \& Billieux, 2014; Gámez-Guadix, Villa-George, \& Calvete, 2012; Siomos, Dafouli, Braimiotis, Mouzas, \& Angelopoulos, 2008), with most 
studies examining samples of White and Asian youth (e.g. Anderson, Steen, \& Stavropoulos, 2017; Kuss et al., 2014; Li et al., 2014). Internationally, the prevalence rates of PIU vary drastically by country and region from $0.8 \%$ (Italy; Poli \& Agrimi, 2012) and 26.7\% (China; Shek \& Yu, 2012). Although the prevalence of PIU in the US is understudied, there is evidence for increasing occurrence of US adolescents with selfreported PIU (Gámez-Guadix, Orue, Smith, \& Calvete, 2013; Gámez-Guadix, VillaGeorge, \& Calvete, 2012; \& Marino, 2017).

\section{Parental Monitoring and PIU}

The association between parental monitoring and PIU is important to examine as parental monitoring can be a potential point of prevention for PIU. Parental monitoring has been defined as parenting practices or involvement in which parents are mindful of their adolescents' whereabouts, peers, and activities (Borawski, Ievers-Landis, Lovegreen, \& Trapl, 2003; Stattin \& Kerr, 2000). A number of studies have examined adolescent risky behaviors among Laitnx and non-Latinx black adolescents and found that an adolescent's perception of parental monitoring serves as a protective factor against engaging in risky behaviors (Borawski et al., 2003; Di-Clemente et al., 2001; Kerr, Stattin, \& Burk, 2010; Lawton \& Gerdes, 2014; Li, Stanton, \& Feigelman, 2000) such as alcohol and drug consumption (DiClemente et al., 2001; Lawton \& Gerdes, 2014). International studies have shown that parental monitoring and similar constructs (e.g., parent-child cohesion; parent involvement) are associated with lower rates of adolescent PIU (Cho, \& Cheon, 2005; Li, Garland, \& Howard, 2014; Xu, Turel, \& Yuan, 2012). In a national study of US adolescent-parent pairs, adolescents who reported increased parental monitoring were less likely to report problematic Internet behaviors 
(Bleakley, Ellithorpe, \& Romer, 2016). Additionally, parental monitoring may be related to a decrease in an adolescent's time spent on a computer (Vaala \& Bleakley, 2015).

\section{Mental Health and PIU}

Many individual mental disorders have been associated with the development of addictive behaviors, including PIU (Anderson, Steen, \& Stavropoulos, 2017;

Stavropoulos, Kuss, et al., 2016). Some factors associated with PIU include lifetime substance use (Liu, Desai, Krishnan-Sarin, Cavallo, \& Potenza, 2011), depression (Liu, Desai, Krishnan-Sarin, Cavallo, \& Potenza, 2011; Kim, Ryu, Chon, Yeun, Choi, Seo, \& Nam, 2006), and anxiety (Lyvers, Karantonis, Edwards, \& Thorberg, 2016). Adolescence is a particularly vulnerable time for developing mental health disorders, such as anxiety, depression, substance use, and PIU (Gámez-Guadix, et. al., 2013). Anxiety disorders are a prevalent psychiatric disorders for adolescents, and are associated with negative outcomes including substance use, mood disorders, and academic problems (HigaMcMillan, Francis, Rith-Najarian, \& Chorpita, 2016). Latino adolescents are a subpopulation of youth who are disproportionately at-risk for experiencing anxiety compared to other ethnicities (Céspedes \& Huey Jr, 2008; Potochnick \& Perreira 2010).

Consequently, non-Latinx black adolescents have a higher rate of anxiety disorders in comparison to White adolescents (Merikangas et al., 2010). Several research studies indicate that non-Latinx black adolescents report more symptoms of depression in comparison to White adolescents (Emslie, Weinberg, Rush, Adams, \& Rintelmann, 1990; Kistner, David-Ferdon, Lopez, \& Dunkel, 2007; Mrug, King, \& Windle, 2016). While Latinx adolescents were found to be at the highest risk of reporting depressive symptoms among all ethnic groups (Kann et al., 2014, Substance Abuse and Mental Health Services 
Administration, 2010). Historically, Latinx adolescents' substance use prevalence rates weighed in-between non-Latinx black (the lowest rate) and White (the highest rate) US adolescents, until the most recent Monitoring the Future data found Latinx adolescents have the highest substance use among the three groups (Johnston, Miech, O'Malley, Bachman, Schulenberg, \& Patrick, 2018).

\section{Sleep Quality and PIU}

Quality sleep is essential for adolescents as it is necessary to prevent cognitive and emotional deficits including engaging in high risk behaviors, and diminished attentional and behavioral regulation (Dahl, 1996; Harrison and Horne, 2000; Tezler et al., 2013). In fact, poor sleep quality has been associated with poor mental health (Galambos, Vargas Lascano, Howard, \& Maggs, 2013; Magnavita \& Garbarino, 2017). Compounding sleep problems, PIU can significantly and negatively affect sleep quality via disruption of the sleep-wake schedule, which in turn can lead to other sleep disturbances or insomnia (Lam, Peng, Mai, \& Jing, 2009; Lam, 2014). Although there is a dearth of information pertaining to the association of PIU on quality sleep among Latinx and non-Latinx black adolescents, previous studies have found PIU has a negative effect on sleep quality among varying samples of adolescents and young adults. Excessive Internet use was found to be associated with insomnia among a sample of college students from a University in Spain (Jenaro, Flores, Gómez-Vela, González-Gil, \& Caballo, 2007). Additionally, increased time spent on the Internet led to the significant disturbance of sleep among a sample of Turkish high school students (Canan, Yildirim, Sinani, Ozturk, Ustunel, \& Ataoglu, 2013). Additional research found evidence that time spent on Internet video gaming (a form of PIU) is associated with sleep delays, irregular 
sleeping patterns, and excessive daytime sleepiness among samples of adolescents from Europe and China (Canan et al., 2013; Choi, Son, Park, Han, Kim, Lee, \& Gwak, 2009; Van den Bulck, 2004).

\section{Academic Performance and PIU}

Existing research reported mixed findings on the effects of PIU on academic performance among varying samples of Chinese and European adolescents. Among these are low school connectedness (Yen, Ko, Yen, Chang, \& Cheng, 2009a), low support from peers and teachers ( $\mathrm{Li}$, Li, Wang, Zhao, \& Bao, 2013; Wang, Zhou, Lu, Wu, Deng, \& Hong, 2011), and poor school performance (Mythily, Qiu, \& Winslow, 2008; Xu et al., 2012). Additionally, involvement with school peers who misuse substances (i.e., drink alcohol) or peers who engage in excessive Internet use are associated with increased likelihood of PIU (Li, Newman, Li, \& Zhang, 2016; Yen, Ko, Yen, Chang, \& Cheng 2009b; Zhang, Chen, Liu, Deng, \& Fang, 2012; Zhou \& Fang, 2015). While conflicting evidence indicates that PIU is associated with low academic performance among varying international samples of youth (Anand, 2007; Brunborg, Mentzoni, \& Frøyland, 2014; Gentile, Lynch, Linder, \& Walsh, 2004; Skoric, Teo, \& Neo, 2009). However, there are differing reports on the effect of PIU on academic performance as some researchers find no significant association between PIU and academic performance among Chinese (Jang, Hwang, \& Choi, 2008) and US adolescents (Liu et al., 2011). Given that previous results are mixed and none of the literature has examined the effects of PIU on academic achievement among Latinx and non-Latinx black adolescents, further examination is needed. 


\section{The Current Study}

As Internet use for leisure and academic or work purposes is a universal behavior among US adolescents, understanding the etiology of PIU is significant to address this growing behavioral health concern. With the pervasiveness of mental health issues and the potentially increasing rate of PIU among US youth, this study aims to fill the gap in literature surrounding the association between mental health and PIU among Latinx and non-Latinx black adolescents.

To address the aforementioned gap in the literature, the current study will examine if PIU will mediate the association between parental monitoring and academic achievement, sleep quality, substance use, anxiety, and depression. More specifically, this study aims to: (1) examine the associations between parental monitoring and various outcomes: addictive behaviors (i.e., PIU and substance use), mental health (i.e., sleep quality, anxiety, and depression), and academic achievement (i.e., GPA); and (2) test the mediation role of PIU the association between PIU and the wellbeing outcomes of academic achievement, sleep quality, substance use, anxiety, and depression among a sample of Latinx and non-Latinx black adolescents.

\section{Method}

\section{Procedure}

Data collection was conducted with participants recruited from an inner-city high school in Southeast Florida. All students attending this public high school were invited to participate in the study. The researchers collaborated with the school to coordinate scheduled group meetings for data collection and teachers assisted with attaining written informed consent from parents. Students who agreed to participate in the survey 
completed an online questionnaire through Qualtrics (2015) via their smartphones or tablets provided by the researchers.

Prior to beginning the questionnaire, written informed consent was obtained from parents or legal guardians for all participants under 18 years old. For those who were 18 years and older, electronic consent was obtained from them via Qualtrics. Approval from the Institutional Review Boards of both the university conducting the research and of the public school board was obtained. Participants read and reviewed the assent form on Qualtrics, and were provided with comprehensive information about the study.

A total of eight group interview sessions with approximately 30 participants per session were held for data collection. Of the 265 students who agreed to participate in the study, 18 students did not provide parental consent and were therefore unable to participate. All participants in the study sample $(n=247)$ also provided assent. Teachers offered students class participation credit for completing the questionnaire. No other remuneration was offered to students who participated or teachers.

\section{Sample}

Participants $(n=247)$ were between the ages of 14 to 19 years old $(M$ age $=16.0$, $\mathrm{SD}=1.2)$. More than half of the sample was female (63.6\%), and $27.1 \%$ were Latinx, 71.7\% were non-Latinx Black, $1.2 \%$ were non-Latinx White. Additionally, $19.8 \%$ were in 9 th grade, $34.8 \%$ were in 10 th grade, $26.3 \%$ in 11 th grade, and $19.1 \%$ were in 12 th grade. Participants self-reported their socioeconomic status (SES), with most of the sample identifying as lower middle class (48.6\%), followed by upper middle class $(39.4 \%)$, poor $(9.2 \%)$ and wealthy $(2.8 \%)$. 


\section{Measures}

Parental Monitoring. Adolescent perceived parental monitoring was measured using an 8-item standardized measure (Stattin \& Kerr, 2000). The scale includes 9 questions (e.g., “Do your parents/guardians know what you do during your free time?”). The responses were scored on a scale of $1=$ always to $5=$ never. Participants' responses were reverse coded for data analysis. Higher scores indicate higher levels of parental monitoring. The internal reliability of the parental monitoring scale in the current sample was $\operatorname{good}(\alpha=.81)$.

Problematic Internet Use. The severity of problematic Internet use was measured using 18-item version of the Problematic Internet Use Questionnaire (PIUQ; Demetrovics, Szeredi, \& Rozsa, 2008). The PIUQ assesses the extent to which respondents experienced obsession with their Internet use (e.g., "How often do you daydream about the Internet?"), neglect of daily obligations and interpersonal relationships due to their Internet use (e.g., "How often do you choose the Internet rather than being with your partner?"), and a loss of control over their Internet use (e.g., "How often does it happen to you that you wish to decrease the amount of time spent online but you do not succeed?"). The PIUQ includes 18 items (categorized in three subscales), and the responses were rated on a five-point Likert-type scale ranging from $1=$ never to $5=$ always. Higher scores indicate higher levels of PIU, no cutoff score has been proposed for the PIUQ. Prior studies have used either one standard deviation above the mean of the PIUQ score as the cutoff point (Demetrovics, Szeredi, \& Rozsa, 2008; Kelly and Gruber, 2010), or employed probabilistic modeling approach to classifying adolescents with problematic Internet use (Koronczai et al., 2011). For instance, Koronczei et al. (2011) 
classified a sample of European youth into two subgroups based on their PIUQ-SF scores: the problematic Internet users and non-problematic users, with a suggested cutoff score of 22. However, this recommended cutoff score has yet to be used to identify problematic Internet use among Latinx and non-Latinx black adolescents. The internal reliability of the PIUQ in the current sample was good $(\alpha=.88)$.

Academic Achievement. Academic achievement was measured by the participant's self-reported grade point average (GPA). GPA is a standard measure of academic achievement among adolescents with behavioral health issues (Brunborg, Mentzoni, \& Frøyland, 2014; McLeod, Uemura, \& Rohrman, 2012). The participants selected a response for GPA from 12 options: 4.0 A+ (97\%-100\%); 4.0 A (93\%-96\%); 3.8-3.7 A- (90\%-92\%); 3.6-3.3 B+ (87\%-89\%); 3.2-3.0 B (83\%-86\%); 2.9-2.7 B- (80\%$82 \%) ; 2.6-2.3 \mathrm{C}+(77 \%-79 \%) ; 2.2-2.0 \mathrm{C}(73 \%-76 \%) ; 1.9-1.7 \mathrm{C}-(70 \%-72 \%) ; 1.6-1.3 \mathrm{D}+$ (67\%-69\%); 1.2-1.0 D (65\%-66\%); 0.9-0.0 F (Below 65). In accordance with the State of Florida's K-20 education code, Chapter $1003 \S 1002.3105$, a student who has earned a GPA of 2.0, based on a 4.0 scale, and has met all testing and credit enrollment requirements, will be awarded a standard high school diploma in a form prescribed by the State Board of Education. For the purposes of analysis, the participants' GPA scores are a continuous scale with a higher score indicating worse GPA.

Substance use and mental health. Substance use, depressive symptoms, anxiety, and sleep quality over the past two weeks were measured using the DSM-5 Cross-Cutting Assessment-Child (APA, 2013). The DSM-5 Cross-Cutting Assessment-Child included questions that assess depression (e.g., "How much have you been bothered by feeling down, depressed, or hopeless?”), anxiety (e.g., "How much have you been bothered by 
feeling nervous, anxious, frightened, worried, or on edge?"), sleep problems (e.g., "How much have you been bothered by problems with sleep that affected your sleep quality?'), and substance misuse (e.g., "How frequent have you been drinking at least 4 drinks in a single day?"). The responses are rated on a five-point Likert-type scale $(1=$ none, $2=$

slight, $3=$ mild, $4=$ moderate, $5=$ severe). A response of mild or greater (i.e., $\geq 3$ ) on any symptoms of a disorder (except for substance misuse) indicates the participant meets the DSM-5 symptom criteria for the specific disorder. For substance misuse related questions, a response of slight or greater (i.e., $\geq 2$ ) on any item indicates the participant is misusing substances. Internal reliability was strong in this sample $(\alpha=.92)$.

Sociodemographic information. Participants' demographic information, including age, sex, grade, family socioeconomic status (SES), academic performance (i.e., GPA) and race/ethnicity was self-reported by participants.

\section{Data Analysis}

Descriptive statistics and correlation analyses were performed on all demographic and main study variables. Structural equation modeling (SEM) was used to examine the direct and indirect effects of parental monitoring and addictive behaviors on adolescents' academic achievement, sleep quality, substance use, anxiety, and depression. SEM allows for the simultaneous examination of the associations between the independent variable of parental monitoring, dependent variables of academic achievement, mental health issues (i.e., depression, anxiety, and sleep quality), substance use, and the mediator of PIU in the sample. In SEM, alternative model specifications can be compared statistically unlike with regression analysis, which is particularly important in a cross-sectional dataset 
where the direction of linkages between variables cannot be revealed inductively and must instead be deducted from prior theory.

Parental monitoring, PIU, substance use, depression, and anxiety were treated as latent variables. In the context of SEM, the CFA is often called 'the measurement model', while the relations between the latent variables is defined as the 'the structural model' (Anderson \& Gerbing, 1988, e.g. Holahan, Moos, Holahan, Brennan, \& Schutte, 2005). Thus, a confirmatory factor analysis (CFA) was first conducted to assess validity of the measurement model. Fit of the measurement model was established before the general SEM model was tested (Anderson \& Gerbing, 1988). Next for the associations between the latent variables, the structural model was used to test the direct paths between 1) parental monitoring and addictive behaviors (i.e., PIU and substance use); 2) between addictive behaviors (i.e., PIU and substance use) and academic achievement; and the indirect paths of parental monitoring to academic achievement through addictive behaviors (i.e., PIU and substance use), 3) depression and anxiety would be significantly related to addictive behaviors (i.e., PIU and substance use); 4) addictive behaviors (i.e., PIU and substance use), depression, and anxiety would have effects on sleep problems; and 5) addictive behaviors (i.e., PIU and substance use) would mediate the effects of depression and anxiety on sleep problems. Depression, anxiety, and sleep quality were treated as observable variables. Indirect effects were calculated using the product-of coefficients approach, such that a total indirect effect is the sum of specific indirect effects through each mediator. Direct and indirect effects were calculated in Mplus 7.11 (Muthen \& Muthen, 2012) using maximum likelihood estimation with robust standard errors (MLR). Accordingly, this SEM tested the direct paths between 1) depression and 
addictive behaviors, 2) anxiety and addictive behaviors, and 3) addictive behaviors and sleep quality; and the indirect paths of depression and anxiety to sleep quality through addictive behaviors. Adolescents' demographic characteristics, including age, sex, and race were used as covariates in all SEM models. The structural component of the final model was confirmed over-identified before evaluating its parameters (Bollen, 1989).

Mplus 7.11 (Muthen \& Muthen, 2012) was used to estimate the measurement model and the SEM models. Maximum Likelihood (ML) was used as the estimator. Mplus' MODEL INDIRECT option was used for obtaining estimates of mediation paths and their statistical significance (Muthén, \& Muthén, 2012). Missing values for the dataset ranged between 0\% - 5.3\%. Mplus uses full information maximum likelihood (FIML) to handle missing values on dependent variables (such as indicators of latent variables) and independent variables that are "brought into the model" by naming their variances in the MODEL statement (Muthén, 2009). To determine the adequacy of model fit, a cutoff of greater than .90 for the CFI and TLI, and a cutoff of less than .06 for the point estimate of the RMSEA was used. Also, the upper bound of the $90 \%$ confidence interval for the RMSEA did not exceed .06 (West, Taylor, \& Wu, 2012).

\section{Results}

\section{Descriptive Statistics}

On average, participants had a score of $39.9(S D=11.9)$ on the PIUQ. About $10 \%$ of the sample responded with "slight" or greater for questions on the DSM-5 CrossCutting Assessment regarding substance use, indicating problems with these substances. Specifically, $12.4 \%(n=29)$ reported alcohol problems, $11.1 \%(n=26)$ reported problems with tobacco use, and $9.8 \%$ of the sample $(n=23)$ reported problems with other 
drugs. In addition, more than half of the sample $(55.1 \%, n=136)$ responded "mild" or greater on items assessing depressive symptoms, half of the sample $(49.8 \%, n=123)$ responded "mild" or greater on any of the items for anxiety symptoms, and $21.9 \%$ of the sample $(n=54)$ responded "mild" or greater on the item for sleep quality.

\section{Measurement Model}

According to pre-specified fit criteria, the model had an adequate fit $\left[\chi^{2}(282, N=\right.$ $247)=397.37, p<.001 ; \mathrm{RMSEA}=.05(90 \% \mathrm{CI}: .03, .05) ; \mathrm{CFI}=.94 ; \mathrm{TLI}=.93]$. The correlation between PIU and parental monitoring was statistically significant $(p<.001$; see Table 1). Three measurement items on the PIUQ (i.e., "How often do you choose the Internet rather than being with your partner?", "How often do you choose the Internet rather than going out with somebody to have some fun?", "How often do you think that you should ask for help in relation to your Internet use?"), and one item on the Parental Monitoring Scale (i.e., "In the last month, have your parents/guardians ever had no idea of where you were at night?") were removed due to low factor loadings $(<.40)$. All factor loadings and variances for the remaining measurement items were $>.40$ and statistically significant $(p<.001)$ and were therefore retained in the CFA measurement model (see Table 2).

\section{Structural Model}

The SEM model that examined the associations between parental monitoring, addictive behaviors (i.e., substance use and PIU), mental health (i.e., depression, anxiety, and sleep quality), and academic achievement had an adequate fit $\left[\chi^{2}(398, N=247)=\right.$ 526.77, $p<.001 ;$ RMSEA $=.04(90 \% \mathrm{CI}: .03, .04) ; \mathrm{CFI}=.93 ; \mathrm{TLI}=.92]$ as seen in Figure 1. Direct effect results for all variables can be found in Table 3. Results of the 
general SEM model revealed that adolescents' self-reported parental monitoring was significantly related to less severe PIU $(b=.27, p<.001)$ and increase in academic achievement $(b=.22, p<.01)$ after controlling for age, sex, and race. Results also yielded a significant negative association between PIU and academic achievement $(b=-$ $.17, p<.05)$, suggesting that higher levels of PIU were significantly associated with a higher academic achievement. In addition to its direct effect on academic achievement, parental monitoring had a significant indirect effect on academic achievement through levels of participants' PIU $(b=.27, p<.001)$. The total effects of parental monitoring on academic achievement — the sum of its direct and mediated effects — was .18 $(p<.05)$. Identifying as female was significantly and positively related to PIU $(b=.25, p<.001)$, and significantly but negatively related to substance use $(b=-.15, p<.05)$ and academic achievement $(b=-.17, p<.01)$. This suggests that girls reported significantly higher levels of PIU compared to boys; and girls reported lower rates of substance use and higher academic achievement than boys.

Additionally, depression was significantly positively related to PIU $(b=.24, p<$ $.05)$ and anxiety was significantly positively related to substance use $(b=.55, p<.001)$ after controlling for an adolescent's age, sex, and race. Moreover, anxiety $(b=.52, p<$ $.001)$, depression $(b=.45, p<.001)$, PIU $(b=.26, p<.01)$, and substance use $(b=.36, p$ $<.001)$ were significantly related to poor sleep quality after controlling for an adolescent's age, sex, and race. Overall, the model explained $18.5 \%$ of the variation in PIU, $20.3 \%$ of substance abuse, $10.9 \%$ of GPA, and $33.4 \%$ of sleep quality in this sample of Latinx and non-Latinx black adolescents. 


\section{Discussion}

For over a decade, research on PIU has examined the deleterious effects of excessive Internet use among adolescents throughout the world (Cheng \& Li, 2014; Kuss, Griffiths, Karila, \& Billieux, 2014, Ferraro, Caci, D'amico, \& Blasi, 2006; GámezGuadix, Villa-George, \& Calvete, 2012; Lin \& Tsai, 2002; Siomos, Dafouli, Braimiotis, Mouzas, \& Angelopoulos, 2008). While this literature exists, few studies have examined PIU among adolescents in the US, and even fewer have included samples of Latinx or non-Latinx Black adolescents. By exploring the mediation role of PIU on the association between PIU and various previously studied factors of academic achievement, sleep quality, substance use, anxiety, and depression, this study hopes to inform future research on variables that may be used with prevention efforts to reduce PIU. Accordingly, the current study aimed to examine the effect of parental monitoring on addictive behaviors (i.e., substance use and PIU), mental health, and academic performance (i.e., GPA) among a sample of US Latinx and non-Latinx Black adolescents, two groups not previously examined.

Overall, the findings suggest that PIU mediates the associations between parental monitoring and the outcomes of academic achievement, sleep quality, substance use, anxiety, and depression. More specifically, higher perceived parental monitoring was directly related to lower PIU among Latinx and non-Latinx Black adolescents. These findings are in line with previous research among White and Asian adolescents that suggests more parental involvement leads to less PIU among international samples of youth and young adults (e.g., Bleakley, Ellithorpe, \& Romer, 2016; Li et al., 2014; Lin et al., 2009). Examining the role of parental monitoring in problematic Internet use may 
generate implications for the development of early interventions that target adolescent's Internet use. As Latinx and non-Latinx Black adolescents engage in more frequent use of the Internet and therefore may be at a higher risk for developing PIU compared to their White peers (Carson et al., 2012; Lenhart, 2015; Liu et al., 2011), an increase in parental monitoring may avert further behavioral health implications. Latinx and non-Latinx black adolescents at risk of developing problematic Internet use may refrain from excessive Internet use if their parents have a better awareness of their child's activities and whereabouts. In addition to parents' awareness and knowledge of their children's activites and whereabouts, parents may also want to monitor their children's Internet use and facilitate regulation of adolescent's Internet use. Subsequently, higher parental monitoring was found to have a positive association with depression and anxiety, the duration of the adolescents' mental health symptoms (i.e. depression and anxiety) were not assessed. Therefore, if the mental health symptoms were ongoing, then the adolescent's parents have more cause for concern and in turn monitor their children more closely. Further longitudinal research is needed to determine causality of mental health symptoms in relations to PIU and parental monitoring.

There was a negative association between PIU and academic achievement, indicating that adolescents with more severe PIU were more likely to have a higher academic achievement. Previous data demonstrates conflicting results on the influence of PIU on academic performance. Among a sample of Chinese adolescents, PIU was a predictor of low academic performance (Hur, 2006). On the other hand, additional studies found no significant association between PIU and grade point average among Chinese adolescents (Jang, Hwang, \& Choi, 2008) or among US adolescents (Liu et al., 2011). 
Despite the historically conflicting data, the current study's findings may be due to adolescents using the Internet excessively to manage their academic work load appropriately. The public school systems in which the data were collected utilized academic course work through an online portal. Thus, as adolescents may be spending an increasing amount of time on the Internet for school work they should regulate their leisure Internet use as this may adversely increase the probability of developing PIU. Also, higher parental monitoring was related to higher academic achievement in the study sample. Similar results indicating perceived parental monitoring had a positive influence on academic achievement were reported in previous research on Latinx (Henry, Merten, Plunkett, \& Sands, 2008) and Non-Latinx black adolescents (Cunningham, Hurley, Foney, \& Hayes, 2002). Thus, it would be beneficial for school educators, counselors, and social workers to inform parents on the potential benefit parental monitoring can have one their children's wellbeing.

Adding to the literature (Anderson et al., 2017), we found that non-Latinx black females were more likely to have problematic Internet use compared to their male counterparts. Studies have suggested that girls have more intensive social media use, while boys play online games and view online pornography more intensively (Dufour et al., 2016; Lenhart, 2015). Evidence also indicates that social media use has been associated with problematic Internet use among girls (Rehbein and Mößle, 2013). Further, a survey study among European young adults reported that female and social media users were more likely to evidence problematic Internet use via smartphones (Lopez-Fernandez et al., 2018). However, aside for online gaming, we did not control for other Internet activities (i.e. social media use) in the regression analysis. Future studies 
that examine gender differences in problematic Internet use should consider varying online activities.

In the current sample, depression was positively associated with PIU suggesting that excessive Internet use may be impacting sleep quality which in turn adolescent's mental health is negative impacted which is increasing their substance use. Future research is needed to determine the sequela of depression and PIU as research has indicated adolescents who meet the criteria for clinical depression are more likely to excessively use the Internet (Spada, 2014). As Internet use may provide immediate gratification and relief from undesirable feelings (such as anxiousness or depression), PIU may be a maladaptive strategy to cope with undesirable emotions (Anderson et al., 2017; Douglas et al., 2008). Additionally, anxiety and depression are often experienced in conjunction (Cicchetti \& Toth, 1998; Ibrahim, Russon, \& Diamond, 2017). Furthermore, the current study reports that PIU, anxiety, depression, and substance use were associated to poor sleep quality. A psychophysical mechanism that may explain the association of PIU on poor sleep quality is that use of a screen (via a smartphone, tablet, or computer) at night leads to a state of high arousal, which interferes with the relaxation process necessary for restful sleep (Spear, 2000). Therefore, it is possible poor sleep quality may lead to anxiousness, and depression, which in turn initiates substance use as a mechanism to aid with sleep and/or to cope with undesirable feelings brought about by anxiety/depression.

The current study provided preliminary, yet important findings suggesting PIU mediates the associations between parental monitoring to the negative outcomes of academic achievement, sleep quality, substance use, anxiety, and depression among 
Latinx and non-Latinx black adolescents in South Florida. As there is evidence that PIU may continue to track into young adulthood (Brunet, Sabiston, O'Loughlin, Chaiton, Low, \& O'Loughlin, 2014), it is imperative for future research to inform on malleable factors to aid PIU prevention efforts. By identifying points of prevention, such as an adolescent's perceived involvement of parental monitoring, clinicians and researchers have evidence on factors that may aid adolescents with PIU. Additionally, future longitudinal research may consider the evidence from this study to investigate depression, anxiety, sleep quality, substance use, and low parental involvement as potential risk factors for PIU.

\section{Limitations}

This study makes a significant contribution to the literature; however, important limitations should be noted. First, the use of cross-sectional data precluded any causal associations between parental monitoring, problematic Internet use, and wellbeing outcomes. Second, as the data were based on participants' self-report, recall bias may exist. Third, as the study was conducted with a convenient sample of Latinx and nonLatinx black adolescents in a Southeastern Florida high school it is not representative of the general population in Southeast Florida or Latinx and non-Latinx black adolescents in the US. Lastly, due to the nature of this explorative study using a limited sample, findings should be cautiously interpreted. Further longitudinal research is needed with larger, representative samples to determine causality.

Despite these limitations, the current study is the first attempt to examine associations between parental monitoring, PIU, mental health, substance use, and academic achievement among Latinx and Non-Latinx Black adolescents. The findings 
have important implications vis-à-vis PIU for future research on Internet-related

behavioral problems among these Latinx and non-Latinx black adolescents. Further,

prevention programs that integrate sex-responsive and culturally-sensitive components

and increase parental monitoring may be necessary for PIU among Latinx and non-Latinx

black adolescents. Mechanisms by which to relay this information to parents is needed.

\section{References}

American Psychiatric Association. (2013). Diagnostic and statistical manual of mental disorders (5th ed.). Arlington, VA: American Psychiatric Publishing. doi:10.1176/appi.books.9780890425596.744053

Anand, V. (2007). A study of time management: The correlation between video game usage and academic performance markers. CyberPsychology \& Behavior, 10, $552-559$.

Anderson, J. C., \& Gerbing, D. W. (1988). Structural equation modeling in practice: A review and recommended two-step approach. Psychological Bulletin, 103(3), 411-423. doi:10.1037/0033-2909.103.3.411

Anderson, E. L., Steen, E., \& Stavropoulos, V. (2017). Internet use and problematic internet use: A systematic review of longitudinal research trends in adolescence and emergent adulthood. International Journal of Adolescence and Youth, 22(4), 430-454. doi:http://dx.doi.org.ezproxy.fiu.edu/10.1080/02673843.2016.1227716

Bleakley, A., Ellithorpe, M., \& Romer, D. (2016). The role of parents in problematic internet use among US adolescents. Media and Communication, 4(3) doi:http://dx.doi.org.ezproxy.fiu.edu/10.17645/mac.v4i3.523

Bollen, K. A. (1989). A new incremental fit index for general structural equation models. Sociological Methods \& Research, 17(3), 303-316. doi: $10.1177 / 0049124189017003004$

Borawski, E. A., Ievers-Landis, C. E., Lovegreen, L. D., \& Trapl, E. S. (2003). Parental monitoring, negotiated unsupervised time, and parental trust: The role of perceived parenting practices in adolescent health risk behaviors. Journal of Adolescent Health, 33(2), 60-70.

Brunborg, G. S., Mentzoni, R. A., \& Frøyland, L. R. (2014). Is video gaming, or video game addiction, associated with depression, academic achievement, heavy episodic drinking, or conduct problems? Journal of Behavioral Addictions, 3(1), 27-32. doi: http://dx.doi.org.ezproxy.fiu.edu/10.1556/JBA.3.2014.002 
Brunet, J., Sabiston, C. M., O'Loughlin, E., Chaiton, M., Low, N. C., \& O'Loughlin, J. L. (2014). Symptoms of depression are longitudinally associated with sedentary behaviors among young men but not among young women. Preventive Medicine, $60,16-20$.

Canan, F., Yildirim, O., Sinani, G., Ozturk, O., Ustunel, T. Y., \& Ataoglu, A. (2013). Internet addiction and sleep disturbance symptoms among Turkish high school students. Sleep and Biological Rhythms, 11(3), 210-213.

Céspedes, Y. M., \& Huey Jr, S. J. (2008). Depression in Latino adolescents: a cultural discrepancy perspective. Cultural Diversity and Ethnic Minority Psychology, 14(2), 168.

Carson, N., Cook, B.L., Chen, C.N., Alegria, M. (2012). Racial/Ethnic Differences in Video Game and Internet use Among US Adolescents with Mental Health and Educational Differences. Journal of Children and Media, 6(4), 450-468. doi:http://dx.doi.org/10.1080/17482798.2012.724592

Choi, K., Son, H., Park, M., Han, J., Kim, K., Lee, B., \& Gwak, H. (2009). Internet overuse and excessive daytime sleepiness in adolescents. Psychiatry and Clinical Neurosciences, 63(4), 455-462.

Cicchetti, D., \& Toth, S. L. (1998). The development of depression in children and adolescents. American Psychologist, 53(2), 221.

Cunningham, M., Hurley, M., Foney, D., \& Hayes, D. (2002). Influence of perceived contextual stress on self-esteem and academic outcomes in African American adolescents. Journal of Black Psychology, 28(3), 215-233.

Dahl, R. E. (1996). The regulation of sleep and arousal: Development and psychopathology. Development and Psychopathology, 8(1), 3-27.

Demetrovics, Z., Szeredi, B., and Rozsa, S. 2008. The three-factor model of Internet addiction: The development of the problematic Internet use questionnaire. Behavior Research Method, 40(2), 563-574. doi:10.3758/BRM.40.2.563

DiClemente, R. J., Wingood, G. M., Crosby, R., Sionean, C., Cobb, B. K., Harrington, K., ... \& Oh, M. K. (2001). Parental monitoring: Association with adolescents' risk behaviors. Pediatrics, 107(6), 1363-1368.

Dong, G., Lu, Q., Zhou, H., \& Zhao, X. (2011). Precursor or sequela: Pathological disorders in people with internet addiction disorder. PloS One, 6(2), 1. doi:http://dx.doi.org.ezproxy.fiu.edu/10.1371/journal.pone.0014703 
Dufour, M., Brunelle, N., Khazaal, Y., Tremblay, J., Leclerc, D., Cousineau, M. M., ... \& Berbiche, D. (2017). Gender difference in online activities that determine problematic internet use. Journal de Thérapie Comportementale et Cognitive, 27(3), 90-98.

Emslie, G. J., Weinberg, W. A., Rush, A. J., Adams, R. M., \& Rintelmann, J. W. (1990). Depressive symptoms by self-report in adolescence: phase I of the development of a questionnaire for depression by self-report. Journal of Child Neurology, 5(2), $114-121$.

Galambos, N. L., Vargas Lascano, D. I., Howard, A. L., \& Maggs, J. L. (2013). Who sleeps best? Longitudinal patterns and covariates of change in sleep quantity, quality, and timing across four university years. Behavioral Sleep Medicine, $11(1), 8-22$.

Gámez-Guadix, M., Orue, I., Smith, P. K., \& Calvete, E. (2013). Longitudinal and reciprocal relations of cyberbullying with depression, substance use, and problematic internet use among adolescents. Journal of Adolescent Health, 53(4), 446-452.

Gámez-Guadix, M., Villa-George, F. I., \& Calvete, E. (2012). Measurement and analysis of the cognitive-behavioral model of generalized problematic Internet use among Mexican adolescents. Journal of Adolescence, 35(6), 1581-1591.

Gentile, D. A., Choo, H., Liau, A., Sim, T., Li, D., Fung, D., \& Khoo, A. (2011). Pathological video game use among youths: A two-year longitudinal study. Pediatrics, 127(2), e319-e329. doi:http://dx.doi.org.ezproxy.fiu.edu/10.1542/peds.2010-1353

Gentile, D. A., Lynch, P. J., Linder, J. R., \& Walsh, D. A. (2004). The effects of violent video game habits on adolescent hostility, aggressive behaviors, and school performance. Journal of Adolescence, 27(1), 5-22.

Harrison, Y., \& Horne, J. A. (2000). The impact of sleep deprivation on decision making: a review. Journal of Experimental Psychology: Applied, 6(3), 236.

Higa-McMillan, C., Francis, S. E., Rith-Najarian, L., \& Chorpita, B. F. (2016). Evidence base update: 50 years of research on treatment for child and adolescent anxiety. Journal of Clinical Child and Adolescent Psychology, 45(2), 91-113.

Holahan, C. J., Moos, R. H., Holahan, C. K., Brennan, P. L., \& Schutte, K. K. (2005). Stress generation, avoidance coping, and depressive symptoms: a 10-year model. Journal of Consulting and Clinical Psychology, 73(4), 658-66. 
Hur, M. H. (2006). Demographic, habitual, and socioeconomic determinants of internet addiction disorder: An empirical study of korean teenagers. Cyberpsychology \& Behavior: The Impact of the Internet, Multimedia and Virtual Reality on Behavior and Society, 9(5), 514-525.

Ibrahim, M., Russon, J., \& Diamond, G. (2017). Attachment-Based Family Therapy for Depressed and Suicidal Adolescents: Development, Research and Clinical Practice. In Handbook of Suicidal Behaviour (pp. 505-521). Springer, Singapore.

Jang, K. S., Hwang, S. Y., \& Choi, J. Y. (2008). Internet addiction and psychiatric symptoms among Korean adolescents. Journal of School Health, 78(3), 165-171.

Jenaro, C., Flores, N., Gómez-Vela, M., González-Gil, F., \& Caballo, C. (2007). Problematic internet and cell-phone use: Psychological, behavioral, and health correlates. Addiction Research \& Theory, 15(3), 309-320.

Johnston, L. D, Miech, R. A, O’Malley, P. M, Bachman, J. G, Schulenberg, J. E., \& Patrick, M. E. (2018). Demographic subgroup trends among adolescents in the use of various licit and illicit drugs, 1975-2017 (Monitoring the Future occasional paper No. 90). Ann Arbor, MI: Institute for Social Research, The University of Michigan. Retrieved from http://www.monitoringthefuture.org/pubs/occpapers/mtf-occ90.pdf.

Kann, L., Kinchen, S., Shanklin, S. L., Flint, K. H., Hawkins, J., Harris, W. A., ... \& Whittle, L. (2014). Youth risk behavior surveillance-United States, 2013. Morbidity and Mortality Weekly Report: Surveillance Summaries, 63(4), 1-168.

Kerr, M., Stattin, H., \& Burk, W. J. (2010). A reinterpretation of parental monitoring in longitudinal perspective. Journal of Research on Adolescence, 20(1), 39-64.

Kim, K., Ryu, E., Chon, M. Y., Yeun, E. J., Choi, S. Y., Seo, J. S., \& Nam, B. W. (2006). Internet addiction in Korean adolescents and its relation to depression and suicidal ideation: a questionnaire survey. International Journal of Nursing Studies, 43(2), 185-192.

Kistner, J. A., David-Ferdon, C. F., Lopez, C. M., \& Dunkel, S. B. (2007). Ethnic and sex differences in children's depressive symptoms. Journal of Clinical Child and Adolescent Psychology, 36(2), 171-181.

Kraut, R., Patterson, M., Lundmark, V., Kiesler, S., Mukophadhyay, T., \& Scherlis, W. (1998). Internet paradox: A social technology that reduces social involvement and psychological well-being? American Psychologist, 53(9), 1017-1031. doi:http://dx.doi.org.ezproxy.fiu.edu/10.1037/0003-066X.53.9.1017 
Kuss, D. J., Griffiths, M. D., Karila, L., \& Billieux, J. (2014). Internet addiction: A systematic review of epidemiological research for the last decade. Current Pharmaceutical Design, 20(25), 4026-4052.

Kuss, D. J., \& Lopez-Fernandez, O. (2016). Internet addiction and problematic internet use: A systematic review of clinical research. World Journal of Psychiatry, 6(1), 143-176. doi:http://dx.doi.org.ezproxy.fiu.edu/10.5498/wjp.v6.i1.143

Lam, L. T. (2014). Internet gaming addiction, problematic use of the internet, and sleep problems: a systematic review. Current Psychiatry Reports, 16(4), 444.

Lam, L. T., Peng, Z. W., Mai, J. C., \& Jing, J. (2009). Factors associated with Internet addiction among adolescents. CyberPsychology \& Behavior, 12(5), 551-555.

Lawton, K. E., \& Gerdes, A. C. (2014). Acculturation and Latino adolescent mental health: Integration of individual, environmental, and family influences. Clinical Child and Family Psychology Review, 17(4), 385-398.

Li, W., Garland, E. L., \& Howard, M. O. (2014). Family factors in Internet addiction among Chinese youth: A review of English-and Chinese-language studies. Computers in Human Behavior, 31, 393-411.

Li, D., Li, X., Wang, Y., Zhao, L., \& Bao, Z. (2013). School connectedness and problematic Internet use in adolescents: A moderated mediation model of deviant peer affiliation and self-control. Journal of Abnormal Child Psychology, 41, 1231-1242.

Li, X., Newman, J., Li, D., \& Zhang, H. (2016). Temperament and adolescent problematic Internet use: The mediating role of deviant peer affiliation. Computers in Human Behavior, 60, 342-350.

Li, X., Stanton, B., \& Feigelman, S. (2000). Impact of perceived parental monitoring on adolescent risk behavior over 4 years. Journal of Adolescent Health, 27(1), 49-56.

Liu, T. C., Desai, R. A., Krishnan-Sarin, S., Cavallo, D. A., \& Potenza, M. N. (2011). Problematic Internet use and health in adolescents: data from a high school survey in Connecticut. The Journal of Clinical Psychiatry, 72(6), 836

Lyvers, M., Karantonis, J., Edwards, M. S., \& Thorberg, F. A. (2016). Traits associated with internet addiction in young adults: Potential risk factors. Addictive Behaviors Reports, 3, 56-60.

doi:http://dx.doi.org.ezproxy.fiu.edu/10.1016/j.abrep.2016.04.001

Magnavita, N., \& Garbarino, S. (2017). Sleep, health and wellness at work: A scoping review. International Journal of Environmental Research and Public Health, 14(11), 1347. 
Merikangas, K. R., He, J. P., Burstein, M., Swanson, S. A., Avenevoli, S., Cui, L., ... \& Swendsen, J. (2010). Lifetime prevalence of mental disorders in US adolescents: results from the National Comorbidity Survey Replication-Adolescent Supplement (NCS-A). Journal of the American Academy of Child \& Adolescent Psychiatry, 49(10), 980-989.

Mrug, S., King, V., \& Windle, M. (2016). Brief report: Explaining differences in depressive symptoms between African American and European American adolescents. Journal of Adolescence, 46, 25-29.

Muthén, L. K., \& Muthén, B. O. (2012). Mplus (version 7). Los Angeles, CA: Muthén \& Muthén.

Muthén, L. K. (2009, June 26). Re: Missing on x variables. [Online forum comment]. Retrieved from: http://www.statmodel.com/discussion/messages/22/4448.html\#POST37434.

Mythily, S., Qiu, S., \& Winslow, M. (2008). Prevalence and correlates of excessive Internet use among youth in Singapore. Annals Academy of Medicine Singapore, $37(1), 9-14$.

Poli, R., \& Agrimi, E. (2012). Internet addiction disorder: prevalence in an Italian student population. Nordic Journal of Psychiatry, 66(1), 55-59.

Potochnick, S. R., \& Perreira, K. M. (2010). Depression and anxiety among firstgeneration immigrant Latino youth: Key correlates and implications for future research. Journal of Nervous and Mental Disease, 198(7), 470-477.

Qualtrics (2015). Qualtrics. Provo: Utah. http://www.qualtrics.com.

Rehbein, F., Mößle, T., 2013. Video game and Internet addiction: is there a need for differentiation?. Sucht, 59, 129-142. doi:10.1024/0939-5911.a000245

Selfhout, M. H. W., Branje, S. J. T., Delsing, M., Ter Bogt, T. F. M., \& Meeus, W. H. J. (2009). Different types of internet use, depression, and social anxiety: The role of perceived friendship quality. Journal of Adolescence, 32(4), 819-833. doi:http://dx.doi.org.ezproxy.fiu.edu/10.1016/j.adolescence.2008.10.011

Siomos, K. E., Dafouli, E. D., Braimiotis, D. A., Mouzas, O. D., \& Angelopoulos, N. V. (2008). Internet addiction among Greek adolescent students. CyberPsychology \& Behavior, 11(6), 653-657.

Skoric, M. M., Teo, L. L. C., \& Neo, R. L. (2009). Children and video games: addiction, engagement, and scholastic achievement. Cyberpsychology \& Behavior, 12(5), 567-572. 
Smith, A. (2014). African Americans and technology use: A demographic portrait. Retrieved from http://www.pewinternet.org/files/2014/01/African-Americansand-Technology-Use.pdf

Spada, M. M. (2014). An overview of problematic Internet use. Addictive Behaviors, 39(1), 3-6.

Spear, L. P. (2000). The adolescent brain and age-related behavioral manifestations. Neuroscience \& Biobehavioral Reviews, 24(4), 417-463.

Stattin, H., \& Kerr, M. (2000). Parental monitoring: A reinterpretation. Child Development, 71(4), 1072-1085.

Stavropoulos, V., Alexandraki, K., \& Motti-Stefanidi, F. (2013). Flow and telepresence contributing to internet abuse: Differences according to gender and age. Computers in Human Behavior, 29(5), 1941-1948.

US Census Bureau. (2017). Retrieved from: http://www.census.gov/

Vaala, S. E., \& Bleakley, A. (2015). Monitoring, mediating, and modeling: Parental influence on adolescent computer and Internet use in the United States. Journal of Children and Media, 9(1), 40-57.

Van den Bulck, J. (2004). Television viewing, computer game playing, and Internet use and self-reported time to bed and time out of bed in secondary-school children. Sleep, 27(1), 101-104.

Wang, H., Zhou, X., Lu, C., Wu, J., Deng, X., \& Hong, L. (2011). Problematic internet use in high school students in Guangdong province, China. PLoS One, 6(5), e19660.

West, S. G., Taylor, A. B., \& Wu, W. (2012). Model fit and model selection in SEM. In R. A. Hoyle (Ed.), Handbook of Structural Equation Modeling (pp.209-231). New York: Guilford Press.

Xu, Z., Turel, O., \& Yuan, Y. (2012). Online game addiction among adolescents: motivation and prevention factors. European Journal of Information Systems, 21(3), 321-340.

Yen, C. F., Ko, C. H., Yen, J. Y., Chang, Y. P., \& Cheng, C. P. (2009a). Multidimensional discriminative factors for Internet addiction among adolescents regarding gender and age. Psychiatry and Clinical Neurosciences, 63(3), 357-364. 
Yen, J. Y., Ko, C. H., Yen, C. F., Chen, C. S., \& Cheng, C. C. (2009b). The association between harmful alcohol use and Internet addiction among college students: Comparison of personality. Psychiatry and Clinical Neurosciences, 63(2), 218224.

Zhang, J., Chen, C., Liu, F., Deng, L., \& Fang, X. (2012). Perceived peers' Internet overuse behavior, attitude on Internet overuse, pressures of Internet using and college students' Internet addiction. Psychological Development and Education, $28,634-640$. 


\title{
MANUSCRIPT 3
}

\begin{abstract}
Research on problematic media use, including the disordered use of video games and/or the Internet, has an international presence in the literature. While market research indicates that US Latinx use the Internet and video games more frequently than nonLatinx US youth, research examining problematic Internet use (PIU) and problematic video gaming (PVG) among Latinx youth is lacking. Accordingly, the current study aims to address if family, cultural, and individual constructs are associated with PIU and PVG among Latinx youth and to examine if PIU and PVG mediate the relation between family, cultural, individual constructs and academic achievement. Multiple regression was used to examine the associations between family, cultural, and individual constructs on PIU/PVG. To test the mediation effects, two separate simple mediation models were tested using PROCESS ${ }^{\odot}$ macro v3.0 for SPSS 25. Regression analysis suggests a significant association between family household composition and PVG. Results from the hypothesized mediation models were not significant. Suggestions for future research to examine critical Latinx cultural values and their influence on behavioral addictions is discussed.
\end{abstract}


The Mediating Effects of Problematic Internet and Video Gaming Behaviors on the Association between Family, Cultural, and Individual Constructs and Academic Achievement Among Latinx Youth

\section{Introduction}

The Internet is widely available and it is an integral part of education for contemporary youth. Despite the potential educational value, many attributes of the Internet (e.g., video gaming, social media use) can cultivate addictive behavior (Shek, Tang, \& Lo, 2009). These addictive behaviors are identified as problematic Internet use (PIU) or Internet Addiction (IA) and problematic video gaming (PVG) or Internet Gaming Disorder (IGD), and are defined as losing control to Internet use or excessive video gaming despite negative consequences (Grant, Potenza, Weinstein, \& Gorelick, 2010). Across different samples and approaches to measurement, somewhere between $3 \%$ and $10 \%$ of adolescents have disordered use of video games and/or the Internet (Griffiths, Kuss, Billieux, \& Pontes, 2016).

Within the United States (US), cross-sectional studies have examined PIU and PVG separately among samples of primarily White and European adolescents (Bleakley, Ellithorpe, \& Romer, 2016; Liu et al., 2011), with little research examining PIU and PVG among Latinx adolescents who are the largest and fastest-growing ethnic minority group in the US (US Census, 2014). The growing US Latinx population is defined by its youth as approximately 17.9 million, of the entire US Latinx population are youth (i.e., under the age of 18 years old; US Census Bureau, 2014). According to a national survey, Latinx youth are $32 \%$ more likely to excessively use the Internet compared to non-Latinx (Lenhart, 2015). Latinx also spend more time on-average playing video games per week 
when compared to non-Latinx (ThinkNow Research Hispanic Omnibus Study, 2014). Moreover, research regarding PIU and PVG generally does not consider the growing population of Latinx youth. Thus, in combination with the potential risk for problematic Internet/video game usage among Latinx youth, there is a need for more focused research on this population. More specifically, there is a dearth of studies on the effect of PIU or PVG among Latinx youth and the role of family, cultural, and individual constructs that may help explain disparities of these problematic behaviors among Latinx adolescents.

Prior work focused on identifying the pathology of PIU or PVG (Aarseth et al., 2016), rather than exploring important contextual components of the phenomena. By investigating potential mediational effects of PIU and PVG on the associations between family household composition, parental attachment, level of acculturation, positive future orientation and academic achievement this study can highlight potential pathways to academic success and hardship among a vulnerable group of youth. Furthermore, as Latinx youth may be at greater risk for developing PIU/PVG, this knowledge may provide insight into malleable factors (i.e. parental attachment) for consideration in future research and prevention efforts of problematic behaviors among Latinx adolescents. Accordingly, the current study aims to address the following questions: (1) How are family, cultural, and individual constructs associated with PIU among Latinx youth; (2) How are family, cultural, and individual constructs associated with PVG among Latinx youth; (3) Does PIU mediate the relation between family, cultural, and individual constructs (i.e., (a) family household composition, (b) parental attachment, (c) level of acculturation, and (d) positive future orientation) and academic achievement? and (4) 
Does PVG mediate the relation between family, cultural, and individual constructs and academic achievement?

\section{Family Household Composition and PIU/PVG}

The fundamental role of family and the cultural value of familismo (family pride and support) within Latinx cultures (Miranda, Bilot, Peluso, Berman, \& Van Meek, 2006) can act as a protective factor for substance use among Latinx adolescents (Castro, Stein,

\& Bentler, 2009). Therefore, family composition may have an important influence on the development of behavioral addictions, such as PIU/PVG, among Latinx adolescents. Many Latinx families in the US also have cultural values (i.e., familismo) that may influence parenting quality and effectiveness, including having a greater number of family members living in a single household, family members immigrating to the US, and the challenges of parenting in an unfamiliar social and cultural environment with limited social and economic resources (Amey \& Albrecht, 1998; Miranda et al., 2006; Sabogal et al., 1987). Although there is currently no literature on family household composition and the behavioral addictions of PIU/PVG, a large study of adolescents living in single-parent households in Florida found that living with a single father predicted increased marijuana use among Latinx adolescent, but not among African Americans or non-Latinx white adolescents (Eitle, 2005).

Prior research has examined the association between family household composition and PIU/PVG among a variety of non-Latinx adolescent samples. Literature examining PIU among European adolescent females, found that those with less PIU had more family members living within their household (Piguet, Berchtold, Akre, \& Suris, 2015). These findings align with those of Rikkers, Lawrence, Hafekost, and Zubrick 
(2016), who found greater PIU and PVG among male and female European youth (ages 11-17) with less family members living in their household. Also, Chinese adolescents living in three generation households (i.e., two-parents and grandparents in the household) were found to be less likely to develop PIU (Xu et al., 2014) or display behavioral problems (Giannakopoulos, Mihas, Dimitrakaki, \& Tountas, 2009).

\section{Parental Attachment and PIU/PVG}

Parental attachment can be defined as the stable connection between a parent and a child when the parent provides support and encourages development of independence while being a source of security and safety (Bowlby, 1982). Numerous studies have demonstrated that parental attachment may serve as a protective factor for reducing risky and addictive behaviors (i.e., substance abuse) among Latinx adolescents and adults (De La Rosa et al., 2015; De La Rosa et al., 2010; Santisteban, Mena, \& Abalo, 2012). Although the association of parental attachment as a protective factor for problematic and risky behaviors among Latinx has been well documented, there is a lack of knowledge on the association between parental attachment and PIU/PVG among Latinx adolescents. Research on this topic among adolescents of other ethnicities has found, for example, more parental attachment to be associated with lower PIU among Greek adolescents (Siomos et al., 2012), while less parental attachment was associated with a greater risk of problematic internet use/addiction among Malayasian adolescents (Soh, Charlton, \& Chew, 2014). Additionally, parental attachment and problematic video gaming/addiction were found to have a significant negative association among South Korean youth (Kim \& Kim, 2015). To date, no studies have explored the association between parental attachment and PIU or PVG among Latinx adolescents. 


\section{Acculturation and PIU/PVG}

Research has found that acculturation can have a positive impact on Latinx youth by allowing them to thrive in the dominant society, however, it can also hinder the protective effects of other cultural factors such as traditional family values and beliefs, family connections, and parenting processes (Bamaca-Colbert, Gayles, \& Lara, 2011; Castro, Stein, \& Bentler, 2009). As Latinx youth typically acculturate to the dominant society more quickly than their parents (Schwartz, Montgomery, \& Briones, 2006), research has suggested that this may lead to disruptions in the parent- child relationship, parental monitoring, and parent-child communication (Gil, Wagner, \& Vega, 2000; Marsiglia, Nagoshi, Parsai, \& Castro, 2012; Martinez, 2006), which in turn, may lead to increased problem behaviors among Latinx adolescents (e.g., substance use; Marsiglia et al., 2012; Martinez, 2006). Although there is extensive research examining the protective effects of acculturation for Latinx adolescents (e.g., De La Rosa, Holleran, Rugh, \& MacMaster, 2005; Gonzales, Deardorff, Formosis, Barr, \& Barrera, 2006; Santisteban, Coatsworth, Briones, Kurtines, \& Szapocznik, 2012), there are no studies exploring the association of acculturation and PIU/PVG among Latinx adolescents. Given the protective effect of acculturation on Latinx adolescents' substance use, behavioral addictions such as PIU and PVG should also be examined.

\section{Positive Future Orientation and PIU/PVG}

Future orientation has been defined as a person's ability to perceive time and future oriented activities (i.e., planning, problem solving, delay of gratification; Trommsdorf, 1983). Research has found that non-Latinx adolescents with higher levels of positive future orientation were significantly less likely to participate in risky 
problematic behaviors (Chen \& Vazsonyi, 2013). Additionally, several studies have found that family constructs (i.e., family household composition and parent-child relationships) influence future orientation in non-Latinx youth (Aronowitz, 2005; MacLeod, 2009; Mccoy, \& Bowen, 2015; Nichols, Kotchick, Barry, \& Haskins, 2010; Nurmi, 1991; Reynolds, 2000). As family household composition and parent-child relationships are essential to the Latinx cultural value of familismo, and future orientation is demonstrated to be associated with a range of health risk behaviors and outcomes among a sample of non- Latinx youth (Prince, Epstein, Nurius, KingGorman-Smith, \& Henry, 2016), the current study proposes to examine the associations between future orientation and PIU/PVG among Latinx adolescents.

\section{Academic Achievement and PIU/PVG}

Latinx students comprise the largest and fastest-growing ethnic minority group in US public schools and they have consistently higher dropout rates compared to White and Black students over a 40-year period (Child Trends, 2016). Existing research on the associations between academic achievement and PIU has been conducted with varying samples of Chinese and European adolescents, with no studies to date examining Latinx youth. Findings from this body of research are equivocal. Among a sample of Korean adolescents, PIU was found to be a predictor of low academic performance (Hur, 2006),

while no significant association between PIU and grade point average was found among a sample of Chinese youth (Jang, Hwang, \& Choi, 2008) and US adolescents (Liu et al., 2011). Substantial evidence indicates that PVG is associated with lower academic achievement among diverse samples of international youth (Anand, 2007; Brunborg, Mentzoni, \& Frøyland, 2014; Gentile, Lynch, Linder, \& Walsh, 2004; Skoric, Teo, \& 
Neo, 2009). Given that the literature on the associations between PIU, PVG, and academic achievement suggests possible associations, and none of the literature has included Latinx adolescents, further examination is needed.

\section{Method}

\section{Procedure}

Participants were recruited from a public high school in Southeast Florida. All the students attending the public high school were invited to participate in the study. The researchers collaborated with the school to coordinate scheduled group meetings for data collection within the students' classrooms. Students who agreed to participate in the survey completed an online questionnaire through REDCap survey software via their smartphones or tablets provided by the researchers. Approval from the Institutional Review Board was obtained. Prior to beginning the questionnaire, participants read and reviewed the assent form and were provided with comprehensive information about the study. Informed consent was obtained from parents or legal guardians for all participants under 18 years old. A total of five group interview sessions with approximately 34 participants per session were held. Of the 170 students who agreed to participate in the study, 11 students did not provide parental consent and were unable to participate. All participants in the study sample $(n=159)$ provided assent. Teachers offered students class participation credit to those that completed the questionnaire. No other remuneration was offered to students who participated or teachers.

\section{Participants}

The sample consisted of 159 Latinx youth, 33\% of whom were foreign born from Latinx counties (i.e., Cuba, Argentina, Dominican Republic, and Peru) and 16\% were 
recent immigrants that came to US within the last 5 years. The participants were between 12 to 19 years of age $(M=16, S D=1.6)$. Half of the sample identified as female $(50.9 \%)$ and one participant identified as transgender male. Regarding their self-reported GPA, 23.3\% reported a GPA of A (range 4.0 - 3.7), 45.9\% reported a GPA of B (range 3.6 2.7), $23.2 \%$ reported a GPA of C (range $2.6-1.7$ ), and 7.6\% reported a lower GPA (range 1.6-0).

\section{Measures}

Problematic Internet Use Questionnaire. Severity of problematic Internet use was measured using the Problematic Internet Use Questionnaire (PIUQ; Demetrovis, Szeredi, \& Rozsa, 2008). The PIUQ consists of 18 items and three subscales of addiction: obsession, neglect, and loss of control. The responses are rated on a five-point Likert-type scale ( $1=$ "Never" to $5=$ "Always"). Higher scores indicate more severe problematic Internet use behaviors. The internal consistency reliability of the PIUQ in the current sample was .84.

Problem Video Game Playing Scale. The Problem Video Game Playing scale was used to measure problematic video gaming among participants (Salguero \& Morán, 2002). This multidimensional measure consists of nine items and measures eight dimensions of addiction: preoccupation, tolerance, loss of control, withdrawal, escape, lies and deception, disregard for consequences, and family/school disruption. Responses were on a five-point Likert-type scale ( $1=$ "Never" to $5=$ "Always") as used in previous research studies (Elliott, Golub, Ream, \& Dunlap, 2012; Ream, Elliott, \& Dunlap, 2011). Responses on the scale were summed, with a higher score indicating more problematic video game playing; no cut-off point was proposed for the scale (Salguero \& Morán, 
2002). The internal consistency reliability of the Problem Video Game Playing scale in the current sample was .97 .

Family Household Composition. A total of 11 questions regarding family household composition were used to assess who lived with the participant. Each participant responded to a statement such as, "I live with both my parents", "I live with only one parent," "I live with my grandparents", "I live with my aunt and uncle". Responses were dichotomous ( $0=$ "No", $1=$ "Yes") and all items were combined with a higher sum indicating a greater number of family members living in the household.

Inventory of Parent and Peer Attachment (IPPA). A revised version of the Inventory of Parent and Peer Attachment (IPPA; Armsden \& Greenberg, 1987) was used to assess the construct of parental attachment. The current study utilized the parental attachment portion, which consists of 50 items and two subscales: paternal parental attachment and maternal parental attachment. Responses were scored using a five-point Likert-type scale $(1=$ "Almost never or never true" to $5=$ "Almost always or always true"). Items were summed, with a higher score indicating higher parental attachment. Numerous other studies support the reliability and validity of the IPPA with youth samples (e.g., Adam \& Chase-Lansdale, 2002; Black \& McCartney, 1997; Formoso et al., 2000; Paterson et al., 1995; Ridenour, Greenberg, \& Cook, 2006). The internal consistency reliability of the IPPA in the current sample was .96 .

Stephenson Multigroup Acculturation Scale. The Stephenson Multigroup Acculturation scale was used to measure youths' level of acculturation (Stephenson, 2000). The scale contains 32 items and two subscales: ethnic society immersion and dominant society immersion. The participants' responses were coded on a four-point 
Likert-type scale ( 1 = "False," to 4 = "True"). The raw scores of all items were summed, with a higher score indicating more acculturation (Giardino \& Procidano, 2012; Weisskirch, 2013; Stephenson, 2000). The internal consistency reliability of the Stephenson Multigroup Acculturation scale in the current sample was .82.

Adolescent Resilience Scale: Positive Future Orientation. A subscale of the Adolescent Resilience Scale (Oshio, Nakaya, Kaneko, \& Nagamine, 2002) was used to assess the construct of future orientation among Latinx youth. The Adolescent Resilience Scale consists of 21 items and has three subscales: novelty seeking, emotional regulation, and positive future orientation. The current study utilized the positive future orientation subscale which consists of five items. Participants answered the questions using a Likerttype scale ( 1 = "Definitely no" to 5 = "Definitely yes"). A total score was computed, with higher scores indicating a higher level of positive future orientation. The internal consistency reliability of the Adolescent Resilience Scale: Future Orientation subscale in the current sample was .89 .

Academic Achievement. Academic achievement was measured by the participant's self-reported grade point average (GPA). GPA is a standard measure of academic achievement among adolescents with behavioral health issues (Brunborg, Mentzoni, \& Frøyland, 2014; McLeod, Uemura, \& Rohrman, 2012). The participants selected a response for GPA from 12 options: 4.0: A through 0.9-0.0: F. In accordance with the State of Florida's K-20 education code, Chapter $1003 \S 1002.3105$, a student who has earned a GPA of 2.0, based on a 4.0 scale, and has met all testing and credit enrollment requirements, will be awarded a standard high school diploma in a form prescribed by the State Board of Education. For the purposes of analysis, the participants' 
GPA scores are a continuous scale with a higher score indicating higher academic achievement.

Demographic Information. Participants' demographic information, including age, biological sex, grade, and ethnicity was self-reported by participants.

\section{Data Analyses}

Preliminary data analyses to test for assumptions of normality, descriptive statistic, and bivariate analysis were conducted using IBM Statistical Package for Social Science (SPSS) Statistics version 25.0 (IBM SPSS Corp, 2013). Log transformations was conducted for the PIU variable that was not normally distributed and positively skewed.

Multiple regression was used to explore the associations between family, cultural, and individual constructs and PIU/ PVG. More specifically, two separate regression models were conducted to examine: (1) How are family, cultural, and individual constructs associated with PIU among Latinx youth; and (2) How are family, cultural, and individual constructs associated with PVG among Latinx youth. Statistical Package for the Social Sciences (SPSS) software was used to run regression models.

To explore the mediation hypothesis, two separate mediation models were conducted using PROCESS ${ }^{\odot}$ macro v3.0 for SPSS 25 while controlling for age and sex. To test the mediation effects, family household composition, parental attachment, acculturation, and positive future orientation were treated as independent variables, PIU and PVG as mediating variables, and academic achievement as the dependent variable, while controlling for age and sex. PROCESS ${ }^{\odot}$ macro employs sophisticated bootstrapping technology for estimating mediation effects and identifies direct and indirect mediation effects (Hayes, 2013; Hayes, 2009). PROCESS ${ }^{\odot}$ macro has been used 
with recent mediation analysis (e.g., Fairchild, MacKinnon, Taborga, \& Taylor, 2009; Hayes \& Preacher, 2010; Imai, Keele, Tingley, \& Yamamoto, 2010; MacKinnon, Fritz, Williams, \& Lockwood, 2007; Preacher \& Hayes, 2004, 2008; Tofighi \& MacKinnon, 2011).

\section{Results}

\section{Preliminary Analysis}

An analysis of standard residuals was carried out, which showed that the data contained no outliers (Std. Residual Min $=-1.78$, Std. Residual Max $=1.79$ ). Tests to see if the data met the assumption of collinearity indicated that multicollinearity was not a concern (Household composition, Tolerance $=.95, V I F=1.05$; Parental attachment, Tolerance $=.94, V I F=1.07$, Acculturation, Tolerance $=.96, V I F=1.04 ;$ Future orientation, Tolerance $=.86, V I F=1.16$, academic achievement, Tolerance $=.84, V I F=$ 1.19). The data met the assumption of independent errors (Durbin-Watson value $=1.32$ ). The histogram of standardized residuals indicated that the data contained approximately normally distributed errors, as did the normal P-P plot of standardized residuals. Descriptive statistics on all measures mean $(M)$ scores and standard deviations $(S D)$ are presented in Table 1. Bivariate analysis (as seen in Table 2) indicated a significant correlation between PIU and PVG and between PIU and future orientation at $p<.01$ There was a negative correlation between PIU and acculturation at $\mathrm{p}<.01$. Lastly, future orientation was correlated with PVG at $\mathrm{p}<.05$.

\section{Regression Analysis}

Simultaneous multiple regression was preformed, and the model found that family household composition, parental attachment, acculturation, future orientation, academic 
achievement did not explain PIU among the sample of Latinx adolescents $(F(4,17)=$ $1.31, \mathrm{p}>.05, \mathrm{R}^{2}=0.53, \mathrm{R}^{2}$ Adjusted $\left.=0.07\right)$. The analysis indicates that family household composition, $(b=-1.045, t=-0.360, p>.05)$, parental attachment $(b=-0.005, t=-0.035, p$ $>.05)$, acculturation $(b=-0.414, t=-1.879, p>.05)$, future orientation $(b=7.940, t=1.291$, $p>.05)$, or academic achievement $(b=0.096, t=0.093, p>.05)$ were significant predictors of PIU.

Simultaneous multiple regression was preformed, and the model found that family household composition, parental attachment, acculturation, future orientation, academic achievement did not explain PVG among the sample of Latinx adolescents $(F(4,16)=$ $1.67, \mathrm{p}>.05, \mathrm{R}^{2}=0.59, \mathrm{R}^{2}$ Adjusted $\left.=0.14\right)$. The analysis indicates that family household composition, $(b=-0.070, t=-0.697, p>.05)$, parental attachment $(b=-0.001, t=-0.152, p$ $>.05)$, acculturation $(b=-0.007, t=0.933, p>.05)$, future orientation $(b=0.453, t=2.213$, $p<.05)$, or academic achievement $(b=-0.036, t=-1.006, p>.05)$ were significant predictors of PVG.

\section{Mediation Analysis}

PIU Model. PROCESS ${ }^{\odot}$ macro mediation was used to investigate the hypothesis that PIU mediates the association between family household composition, parental attachment, acculturation, future orientation and academic achievement while controlling for sex and age. Regression analysis was used to investigate the hypothesis that PIU mediates the relation between family household composition, parental attachment, acculturation, future orientation, and academic achievement while controlling for sex and age. The overall model explained $22 \%$ of the variance in academic achievement $\left(\mathrm{R}^{2}=\right.$ $.22)$ and was not significant $[\mathrm{F}(6,37)=1.75, p=.14]$. As seen in Figure 1, results 
indicated that family household composition, $(b=-0.11, t(37)=-1.10, p<.01)$, parental attachment, $(b=0.01, t(37)=-0.06, p>.05)$, acculturation, $(b=-0.04, t(37)=-1.31, p$ >. 05), and future orientation, $(b=-0.01, t(37)=-1.04, p>.05)$, were not significant predictors of PIU. The b-bath coefficient indicated that PIU was not a significant predictor of academic achievement, $(b=0.01, t(36)=0.01, p>.05)$. The c-paths indicated that family household composition was not a significant predictor of academic achievement $(b=-0.49, t(36)=-0.70, p>.05)$, parental attachment was not a significant predictor of academic achievement $(b=-0.01, t(36)=-1.38, p>.05)$, acculturation was not a significant predictor of academic achievement $(b=-0.04, t(36)=-1.31, p>.05)$, and future orientation was not a significant predictor of academic achievement $(b=-0.09$, $t(36)=-0.87, p>.05)$. These results do not support the mediational hypothesis. Family household composition was not a significant predictor of academic achievement after controlling for the mediator, PIU, $(b=0.06, t(37)=0.13, p>.05)$, consistent with full mediation. Parental attachment was not a significant predictor of academic achievement after controlling for the mediator, PIU, $(b=-0.01, t(37)=-1.38, p>.05)$. Acculturation was not a significant predictor of academic achievement after controlling for the mediator, PIU, $(b=-0.04, t(37)=-1.22, p>.05)$, consistent with full mediation. Future orientation was not a significant predictor of academic achievement after controlling for the mediator, PIU, $(b=-0.06, t(37)=-0.66, p>.05)$, consistent with full mediation.

PVG Model. PROCESS ${ }^{\odot}$ macro mediation was used to investigate the hypothesis that PVG mediates the association between family household composition, parental attachment, acculturation, future orientation and academic achievement while controlling for sex and age. The overall model explained $21 \%$ of the variance in academic 
achievement $\left(\mathrm{R}^{2}=.21\right)$ and was not significant $[\mathrm{F}(6,38)=1.67, p=.15]$. As seen in Figure 2, results suggested that family household composition, $(b=-0.70, t(38)=-2.83$, $p<.01)$, parental attachment, $(b=0.03, t(38)=0.12, p>.05)$, acculturation, $(b=-0.01, t$ $(38)=-0.22, p>.05)$, and future orientation, $(b=-0.01, t(38)=-0.24, p>.05)$, were not significant predictors of PVG. The b-path coefficients indicated that PVG was not a significant predictor of academic achievement, $(b=-0.04, t(37)=-0.08, p>.05)$. The $\mathrm{c}-$ paths suggested that family household composition $(b=-0.21, t(37)=-0.76, p>.05)$, parental attachment $(b=-0.63, t(37)=-1.52, p>.05)$, acculturation $(b=-0.04, t(37)=-$ $1.41, p>.05)$, and future orientation $(b=-0.06, t(37)=-0.65, p>.05)$, were not significant predictors of academic achievement. These results do not support the mediational hypothesis. Family household composition was not a significant predictor of academic achievement after controlling for the mediator PVG $(b=0.11, t(38)=0.26, p>$ .05). Parental attachment was not a significant predictor of academic achievement after

controlling for the mediator, PVG, $(b=-0.63, t(38)=-1.54, p>.05)$, consistent with full mediation. Acculturation was not a significant predictor of academic achievement after controlling for the mediator, PVG, $(b=-0.04, t(38)=-1.39, p>.05)$, consistent with full mediation. Future orientation was not a significant predictor of academic achievement after controlling for the mediator, PVG, $(b=-0.06, t(38)=-0.63, p>.05)$, consistent with full mediation.

\section{Discussion}

The objective of the current study was twofold. The first goal was to examine if family, cultural, and individual constructs were associated with PIU and PVG among Latinx youth. The second was to explore if PIU or PVG mediated the association 
between family, cultural, and individual constructs (i.e., family structure, parental attachment, level of acculturation, and positive future orientation) and academic achievement. Although most of the findings were not statistically significant, this study makes an important contribution to the literature as it is among the first to examine the emerging behavioral health issues of PIU and PVG among Latinx youth and consider predictor variables that are often associated with Latinx cultural values. Nevertheless, the current study's findings examined variables fundamental to the well-being of Latinx adolescents (e.g., acculturation, parental attachment), and further investigation using a larger sample of Latinx adolescents from a larger geographical area in the US is advised.

In Latinx families, culture is intertwined with family dynamics and can influence an adolescent's behaviors. Although the current study found no significant associations between family household composition and PIU, PVG, or academic achievement, a limitation was not examining the cultural constructs specific to Latinx family dynamics which is the cultural value of familismo (Castro et al., 2006). Hence, further research is needed to examine how family composition may be related to familismo and, in turn, to parental relationships via parental monitoring and their influence on behavioral addictions such as PIU and PVG.

Another limitation to this study was not examining the influence of Latinx cultural identity as a protective factor against behavioral addictions that may also encourage positive future orientation and increase academic achievement. Cultural identity is often prominent among recent immigrant youth and can promote resilience in this population (Cardoso \& Thompson, 2010). In the current study, approximately onethird (33\%) of the sample were foreign born and less than a quarter (16\%) were recent 
immigrants. Due to the small numbers, the study was unable to explore the influential construct of Latinx cultural values. Latinx cultural values, in comparison to American culture, may have a differential effect on family processes (e.g., parental communication and parental monitoring) and on behavioral outcomes. Examining the direct and indirect effects of cultural values on family processes and youth substance use can help inform clinical and prevention efforts specific to Latinx adolescents (Prado, Szapocznik, Maldonado-Molina, Schwartz, \& Pantin, 2008).

Identifying key factors that can help inform clinical and prevention efforts are essential to reduce health risks and disparities among Latinx youth. Latinx youth are at higher risk for substance use, approximately two thirds of Latinx youth live in poverty or low-income household, and $34 \%$ of the national high school dropout rate consists of Latinx adolescents (Murphey et al., 2014). Among Latinx dropouts, the highest proportion are immigrants, with foreign-born youth accounting for nearly $21 \%$ of the total dropout rate (Murphey et al., 2014). Although the current study did not find any association between family, cultural, individual constructs and academic achievement, there is evidence that Latinx are at higher risk of low academic achievement. In conclusion, considering the aforementioned disparities among Latinx adolescents, examining additional factors (e.g. parental monitoring, parental involvement, PIU, PVG) that can serve as points of intervention and prevention for academic achievement can greatly increase the quality of life for this population.

It should also be noted, that the current study's non-significant findings in relation to parental attachment are of particular interest as previous research has indicated parental attachment influences PIU and PVG among non-Latinx youth (e.g., Kim \& Kim, 
2015; Soh, Charlton, \& Chew, 2014). Additionally, there is substantial literature indicating that parental attachment and parental involvement serve as protective factors for Latinx adolescents. More specifically, parental involvement (i.e., parents frequently engaging in activities and communication with their child) is key in providing social support to youth, developing positive parent-child relationships, and in preventing substance use (De La Rosa \& White, 2001). Additionally, parental involvement with Latinx adolescents has been found to be inversely associated with substance use (Lindenberg et al, 1994; Parsai, Voisine, Marsiliga, Kulis, \& Nieri, 2009), therefore it may be prudent to examine the association between parental involvement and other types of behavioral addiction (i.e., PIU/PVG) in future studies.

Another essential variable of interest among Latinx adolescents is that of acculturation. In the current study, the measure for acculturation was two-dimensional, measuring the adolescent's level of acculturation on two subscales: dominant society immersion and ethnic society immersion. Therefore, the measure did not take into consideration the multidimensional nature of acculturation. That is, Latinx adolescents may identify as bi-cultural by conforming to American culture when in school or work, while identifying with Latinx culture and values when at home or with peers (De La Rosa, 2009). Therefore, this is a limitation in the current study as acculturation is a complex process that is unique to Latinx adolescents and is often related to additional key factors such as that of acculturation related stress.

Historically, research regarding the association between acculturation and Latinx youth health behaviors has produced consistent culturally relevant findings related to substance use and dependence (Caetano \& Clark, 2003; De La Rosa, Holleran, Rugh, \& 
MacMaster, 2005; Epstein, Botvin, \& Diaz, 2001; Santisteban et al., 2012; Szapocznik et al., 2007; Warner et al., 2006). For recent immigrants, acculturation is a socialization process into the dominant society and may cause internal conflict as individuals attempt to preserve their cultural values while adopting conflicting societal norms (Marsiglia, Kulis, Wagstaff, Elek, \& Dran, 2005). Although the current study found non-significant associations between acculturation and behavioral health, it should be noted that the sample primarily consisted of non-immigrant Latinx adolescents (67\%). Additionally, the current study did not assess for acculturative stress in the portion of the sample that were recent immigrants $(16 \%)$. Acculturative stress is an important construct to consider as adjusting to American culture can be stressful. Often Latinx cultural values and norms emphasize family while American culture values and norms emphasize individualism over family (Marsiglia, Nagoshi, Parsai, \& Gonzalez-Castro, 2012), which may be a source of acculturative stress.

The results of the two mediation models were not statistically significant; thus, the current study fails to reject the null hypotheses. The nature of the current study was exploratory, and these findings are still valuable as some of the variables examined (e.g., future orientation) and their association to PIU and PVG were previously unknown. Additionally, the sample was comprised of mainly US born Latinx adolescents, with only one third $(33.3 \%)$ being foreign born suggesting much of the sample may have a higher level or acculturation or are bicultural. Future research examining PIU and PVG among this population should explore a larger sample of recently immigrated Latinx adolescents to account for variability for other constructs associated with acculturation (e.g., acculturative stress) that may be associated with behavioral addictions. Additionally, 
future research should consider examining additional variables, such as parental involvement, as malleable factors for potential points of intervention and prevention of behavioral health issues.

\section{Limitations}

Although the current study provides important knowledge, there are several limitations. First, this study incorporates a cross-sectional design, therefore no temporal sequence can be observed. Second, the use of self-reported measures incurs the risk of response bias and/or social desirability bias. Also, each measure incorporated a different measurement of time; for example, the IPPA examines parental attachment over a lifetime, while PIUQ examines problematic Internet behaviors within the last 6 months. Lastly, the study includes the use of a non-random convenience sample and therefore no inferences can be made. In addition, the sample consists of only adolescents currently enrolled in one public high school and is not representative of the general population in Southeast Florida or Latinx in the US. Despite these limitations, the study provided insight into the non-significant effects of PIU and PVG as mediators for the associations between family, cultural, and individual constructs with Latinx youth. Future research should consider examining previously discussed cultural specific constructs to generate knowledge about problematic Internet and video gaming behaviors among US Latinx youth that will aid clinicians and researchers to better serve Latinx individuals, families, communities, and society.

\section{References}

Aarseth, E., Bean, A. M., Boonen, H., Colder Carras, M., Coulson, M., Das, D., ... \& Haagsma, M. C. (2016). Scholars' open debate paper on the World Health Organization ICD-11 Gaming Disorder proposal. Journal of Behavioral Addictions, (0), 1-4. 
Amey, C. H., \& Albrecht, S. L. (1998). Race and ethnic differences in adolescent drug use: The impact of family structure and the quantity and quality of parental interaction. Journal of Drug Issues, 28(2), 283-298.

Anand, V. (2007). A study of time management: The correlation between video game usage and academic performance markers. CyberPsychology \& Behavior, 10, $552-559$.

Aronowitz, T. (2005). The role of "envisioning the future", in the development of resilience among at-risk youth. Public Health Nursing, 22(3), 200-208.

Brunborg, G. S., Mentzoni, R. A., \& Frøyland, L. R. (2014). Is video gaming, or video game addiction, associated with depression, academic achievement, heavy episodic drinking, or conduct problems? Journal of Behavioral Addictions, 3(1), 27-32. doi:http://dx.doi.org.ezproxy.fiu.edu/10.1556/JBA.3.2014.002

Cardoso, J. B., \& Thompson, S. J. (2010). Common themes of resilience among Latino immigrant families: A systematic review of the literature. Families in Society, 91(3), 257-265.

Castro, F. G., Stein, J. A., \& Bentler, P. M. (2009). Ethnic pride, traditional family values, and acculturation in early cigarette and alcohol use among Latino adolescents. The Journal of Primary Prevention, 30(3-4), 265-292.

Chen, P., \& Vazsonyi, A. T. (2013). Future orientation, school contexts, and problem behaviors: A multilevel study. Journal of Youth and Adolescence, 42(1), 67-81.

Child Trends. (2016). Child Trends' calculations of U.S. Census Bureau, school enrollment-social and economic characteristics of students: Detailed tables. Retrieved from https://www.census.gov/data/tables/time-series/demo/schoolenrollment/cps-historical-time-series.html

De La Rosa, M., Dillon, F.R., Ganapati, N.E., Rojas, P., Pinto, E., Prado, G. (2010). Mother-Daughter Attachment and Drug Abuse Among Latinas in the United States. Journal of Drug Issues, 10(2), 379-404. doi:http://dx.doi.org/10.15288/jsad.2015.76.307

De La Rosa, M. R., Holleran, L. K., Rugh, D., \& MacMaster, S. A. (2005). Substance abuse among US Latinos: A review of the literature. Journal of Social Work Practice in the Addictions, 5(1-2), 1-20.

De La Rosa, M., Huang, H., Rojas, P., Dillon, F.R., Lopez-Quintero, C., Li, T., \& Ravelo, G. (2015). Influence of Mother-Daughter Attachment on Substance Use: A Longitudinal Study of a Latina Community-Based Sample. Journal of Studies on Alcohol and Drugs, 76(2), 307-316. 
De La Rosa, M., \& White, M. S. (2001). A review of the role of social support systems in the drug use behavior of Hispanics. Journal of Psychoactive Drugs, 33(3), 233240.

Elliott, L., Golub, A., Ream, G., \& Dunlap, E. (2012). Video Game Genre as Predictor of Problem Use. Cyberpsychology, Behavior, and Social Networking, 15(3), 155161. doi:http://dx.doi.org/10.1089/cyber.2011.0387

Eitle, D. (2005). The moderating effects of peer substance use on the family structureadolescent substance use association: Quantity versus quality of parenting. Addictive Behaviors, 30(5), 963-980.

Gentile, D. A., Lynch, P. J., Linder, J. R., \& Walsh, D. A. (2004). The effects of violent video game habits on adolescent hostility, aggressive behaviors, and school performance. Journal of Adolescence, 27(1), 5-22.

Giannakopoulos, G., Mihas, C., Dimitrakaki, C., \& Tountas, Y. (2009). Family correlates of adolescents' emotional/behavioural problems: evidence from a Greek schoolbased sample. Acta Paediatrica, 98(8), 1319-1323.

Giardino, J. C., \& Procidano, M. E. (2012). Muscle dysmorphia symptomatology: A cross-cultural study in Mexico and the United States. International Journal of Men's Health, 11(1), 83-103.

Gil, A. G., Wagner, E. F., \& Vega, W. A. (2000). Acculturation, familism, and alcohol use among Latino adolescent males: Longitudinal relations. Journal of Community Psychology, 28(4), 443-458.

Gonzales, N. A., Deardorff, J., Formoso, D., Barr, A., \& Barrera, J., M. (2006). Family mediators of the relation between acculturation and adolescent mental health. Family Relations, 55(3), 318-330.

Grant, J. E., Potenza, M. N., Weinstein, A., \& Gorelick, D. A. (2010). Introduction to Behavioral Addiction. American Journal of Drug Alcohol Abuse, 36(5), 233-241.

Griffiths, M. D., Kuss, D. J., Billieux, J., \& Pontes, H. M. (2016). The evolution of Internet addiction: A global perspective. Addictive Behaviors, 53, 193-195.

Griffiths, M.D., Kuss, D.J. \& King, D.L. (2012). Video game addiction: Past, present and future. Current Psychiatry Reviews, 8, 308-318. doi:http://dx.doi.org/10.2174/157340012803520414

Griffiths, M.D. \& Meredith, A. (2009). Videogame addiction and treatment. Journal of Contemporary Psychotherapy, 39(4), 47-53. 
Hayes, A. F. (2009). Beyond Baron and Kenny: Statistical mediation analysis in the new millennium. Communication Monographs, 76, 408-420.

Hayes, A.F. (2013). Introduction to mediation, moderation, and conditional process analysis: A regression-based approach. New York, NY: The Guilford Press.

Hur, M. H. (2006). Demographic, habitual, and socioeconomic determinants of internet addiction disorder: An empirical study of korean teenagers. Cyberpsychology \& Behavior: The Impact of the Internet, Multimedia and Virtual Reality on Behavior and Society, 9(5), 514-525.

Imai, K., Keele, L., Tingley, D., \& Yamamoto, T. (2010). Causal mediation analysis using R. In Advances in Social Science Research Using R (pp. 129-154). Springer, New York, NY.

Jang, K. S., Hwang, S. Y., \& Choi, J. Y. (2008). Internet addiction and psychiatric symptoms among Korean adolescents. Journal of School Health, 78(3), 165-171.

Kim, K., \& Kim, K. (2015). Internet game addiction, parental attachment, and parenting of adolescents in South Korea. Journal of Child \& Adolescent Substance Abuse, 24(6), 366-371.

K-12 Education Code, Fla Stat $\S 1002.3105$ (1995 \& Supp. 2017).

Lenhart, A. (2015). Teens, Social Media \& Technology Overview 2015. Pew Research Center. Retrieved from http://www.pewinternet.org/2015/04/09/teens-socialmedia-technology-2015/

MacKinnon, D. P., Fritz, M. S., Williams, J., \& Lockwood, C. M. (2007). Distribution of the product confidence limits for the indirect effect: Program PRODCLIN. Behavior Research Methods, 39(3), 384-389.

MacLeod, J. (2009). Ain't no makin' it: Aspirations and attainment in a low-income neighborhood (3rd ed.) [electronic version]. Boulder, CO: Westview Press.

Marsiglia, F. F., Nagoshi, J. L., Parsai, M., \& Castro, F. G. (2012). The influence of linguistic acculturation and parental monitoring on the substance use of Mexicanheritage adolescents in predominantly Mexican enclaves of the Southwest US. Journal of Ethnicity in Substance Abuse, 11(3), 226-241.

Martinez Jr, C. R. (2006). Effects of differential family acculturation on Latino adolescent substance use. Family Relations, 55(3), 306-317. 
Mccoy, H., \& Bowen, E. A. (2015). Hope in the social environment: Factors affecting future aspirations and school self-efficacy for youth in urban environments. Child \& Adolescent Social Work Journal, 32(2), 131-141. doi:http://dx.doi.org.ezproxy.fiu.edu/10.1007/s10560-014-0343-7

McLeod, J. D., Uemura, R., \& Rohrman, S. (2012). Adolescent mental health, behavior problems, and academic achievement. Journal of Health and Social Behavior, 53(4), 482-97.

Miranda, A. O., Bilot, J. M., Peluso, P. R., Berman, K., \& Van Meek, L. G. (2006). Latino families: The relevance of the connection among acculturation, family dynamics, and health for family counseling research and practice. The Family Journal, 14(3), 268-273.

Nichols, T. M., Kotchick, B. A., Barry, C. M., \& Haskins, D. G. (2010). Understanding the educational aspirations of African American adolescents: Child, family, and community factors. Journal of Black Psychology, 36(1), 25-48.

Nurmi, J. (1991). How do adolescents see their future? A review of the development of future orientation and planning. Developmental Review, 11(1), 1-59.

Oshio, A., Nakaya, M., Kaneko, H., \& Nagamine, S. (2002). Development and validation of an Adolescent Resilience Scale. Japanese Journal of Counseling Science, 35, $57-65$.

Piguet, C., Berchtold, A., Akre, C., \& Suris, J. (2015). What keeps female problematic internet users busy online? European Journal of Pediatrics, 174(8), 1053-1059. doi: http://dx.doi.org.ezproxy.fiu.edu/10.1007/s00431-015-2503-y

Prado, G., Szapocznik, J., Maldonado-Molina, M. M., Schwartz, S. J., \& Pantin, H. (2008). Drug use/abuse prevalence, etiology, prevention, and treatment in Hispanic adolescents: A cultural perspective. Journal of Drug Issues, 38(1), 5-36.

Preacher, K. J., \& Hayes, A. F. (2004). SPSS and SAS procedures for estimating indirect effects in simple mediation models. Behavior Research Methods, Instruments, \& Computers, 36(4), 717-731.

Preacher, K. J., \& Hayes, A. F. (2008). Asymptotic and resampling methods for estimating and comparing indirect effects. Behavior Research Methods, 40, 879891.

Prince, D. M., Epstein, M., Nurius, P. S., King, K., Gorman-Smith, D., \& Henry, D. B. (2016). Assessing future expectations of low-income minority young men: Survival-threats and positive expectations. Journal of Child and Family Studies, 25(7), 2089-2101. 
Ream, G. L., Elliott, L. C., \& Dunlap, E. (2011). Playing video games while using or feeling the effects of substances: Associations with substance use problems. International Journal of Environmental Research and Public Health, 8(10), 39793998. doi:http://dx.doi.org.ezproxy.fiu.edu/10.3390/ijerph8103979

Reynolds, A. J. (2000). Educational success in high-risk settings: Contributions of the Chicago longitudinal study. Journal of School Psychology, 37(4), 345-354.

Rikkers, W., Lawrence, D., Hafekost, J., \& Zubrick, S. R. (2016). Internet use and electronic gaming by children and adolescents with emotional and behavioural problems in Australia - results from the second child and adolescent survey of mental health and wellbeing. BMC Public Health, 16 doi:http://dx.doi.org.ezproxy.fiu.edu/10.1186/s12889016-3058-1

Salguero, R.A.T.; Morán, R.M.B. (2002). Measuring problem video game playing in adolescents. Society for the Study of Addiction to Alcohol and Other Drugs, 97,16011606.

Santisteban, D.A., Mena, M.P., \& Abalo, C. (2012). Bridging diversity and family systems: Culturally informed and flexible family-based treatment for Hispanic adolescents. Couple and Family Psychology: Research and Practice, 2(4), 246263. doi:http://dx.doi.org/10.1037

Santisteban, D. A., Coatsworth, J. D., Briones, E., Kurtines, W., \& Szapocznik, J. (2012). Beyond acculturation: An investigation of the relationship of familism and parenting to behavior problems in hispanic youth. Family Process, 51(4), 470-82.

Schwartz, S. J., Montgomery, M. J., \& Briones, E. (2006). The role of identity in acculturation among immigrant people: Theoretical propositions, empirical questions, and applied recommendations. Human development, 49(1), 1-30.

Shek, D. T., \& Yu, L. (2012). Internet addiction phenomenon in early adolescents in Hong Kong. The Scientific World Journal, 2012.

Siomos, K., Floros, G., Fisoun, V., Evaggelia, D., Farkonas, N., Sergentani, E., . . . Geroukalis, D. (2012). Evolution of internet addiction in greek adolescent students over a two-year period: The impact of parental bonding. European Child \& Adolescent Psychiatry, 21(4), 211-219. doi:http://dx.doi.org.ezproxy.fiu.edu/10.1007/s00787-012-0254-0

Skoric, M. M., Teo, L. L. C., \& Neo, R. L. (2009). Children and video games: addiction, engagement, and scholastic achievement. Cyberpsychology \& Behavior, 12(5), 567-572. 
Soh, P. C. H., Charlton, J. P., \& Chew, K. W. (2014). The influence of parental and peer attachment on Internet usage motives and addiction. First Monday, 19(7).

Stephenson, M. (2000). Development and validation of the Stephenson Multigroup Acculturation Scale (SMAS). Psychological Assessment, 12(1), 77.

ThinkNow Research Hispanic Omnibus Study (2014). Retrieved from http://www.hispanicgamers.com/\#demographics

Tofighi, D., \& MacKinnon, D. P. (2011). R Mediation: An R package for mediation analysis confidence intervals. Behavior Research Methods, 43(3), 692-700.

US Census Bureau. (2014). Retrieved from: http://www.census.gov/

Weisskirch, R. S. (2013). Family relationships, self-esteem, and self-efficacy among language brokering mexican american emerging adults. Journal of Child and Family Studies, 22(8), 1147-1155. doi:http://dx.doi.org.ezproxy.fiu.edu/10.1007/s10826-012-9678-x

Xu, J., Shen, L., Yan, C., Hu, H., Yang, F., Wang, L., . . Shen, X. (2014). Parentadolescent interaction and risk of adolescent internet addiction: A population-based study in shanghai. BMC Psychiatry, 14, 112.

doi:http://dx.doi.org.ezproxy.fiu.edu/10.1186/1471-244X-14-112 


\section{Tables for Manuscript 1}

Table 1

Percentage and Total Sum of Problem Video Game Playing Scale Items by Dimension

\begin{tabular}{lcc}
\hline PVP Item & Percent & Sum $(n)$ \\
\hline 1. Preoccupation & $40.0 \%$ & 64 \\
2. Tolerance & $31.9 \%$ & 51 \\
3. Loss of Control & $49.7 \%$ & 79 \\
4. Withdrawal & $26.4 \%$ & 42 \\
5. Escape & $36.1 \%$ & 57 \\
6. Loss of Control & $56.3 \%$ & 90 \\
7. Lies and Deception & $31.6 \%$ & 50 \\
8. Disregard for physical/ psychological consequences & $9.4 \%$ & 15 \\
9. Family/schooling disruption & $25.0 \%$ & 40 \\
\hline
\end{tabular}


Table 2

Problem Video Game Playing Mean Scores, Standard Deviations (SD) by Sex and Age

\begin{tabular}{lcccc}
\hline Age Range by Years & All $(n)$ & Male $M(\mathrm{SD})$ & Female $M(\mathrm{SD})$ & Total $M(\mathrm{SD})$ \\
\hline Elementary School Age & 76 & $4.47(1.83)$ & $2.66(2.04)$ & $3.57(2.13)$ \\
Middle School Age & 38 & $3.60(2.21)$ & $2.67(2.17)$ & $3.16(2.21)$ \\
High School Age & 45 & $2.00(1.56)$ & $2.04(1.37)$ & $2.02(1.44)$ \\
Total & 159 & $3.62(2.11)$ & $2.47(1.89)$ & $3.07(2.12)$ \\
\hline
\end{tabular}

Note. $M=$ Mean; $\mathrm{SD}=$ Standard Deviations 
Table 3

Two-Way ANOVA of Problem Video Game Playing Scale Mean Scores by Sex and Age

\begin{tabular}{lcccccc}
\hline Variable & SS & df & MS & F & $p$ & ES \\
\hline Sex & 29.57 & 1 & 29.57 & 8.35 & .004 & .052 \\
Age & 67.56 & 2 & 33.78 & 9.54 & $<.001$ & .111 \\
Sex by Age & 24.43 & 2 & 12.21 & 32.45 & .03 & .043 \\
\hline Note. SS = sum of squares; df = degrees of freedom; MS = mean square; ES = effect size
\end{tabular}


Tables and Figure for Manuscript 2

Table 1. Correlation coefficients for all latent variables.

\begin{tabular}{|c|c|c|c|c|c|c|c|}
\hline & $\begin{array}{c}\text { Parental } \\
\text { monitoring }\end{array}$ & PIUQ & $\begin{array}{l}\text { Academic } \\
\text { achievement }\end{array}$ & $\begin{array}{c}\text { Substance } \\
\text { use }\end{array}$ & Sleep quality & Anxiety & Depression \\
\hline Parental monitoring & 1 & & & & & & \\
\hline PIUQ & $.267^{* * * *}$ & 1 & & & & & \\
\hline Academic achievement & $.170^{*}$ & $-.150^{*}$ & 1 & & & & \\
\hline Substance use & -.081 & -.067 & .116 & 1 & & & \\
\hline Sleep quality & $.170^{*}$ & $.282^{* * * *}$ & .073 & $.306^{* * *}$ & 1 & & \\
\hline Anxiety & $.149^{+}$ & .045 & .102 & $.511^{* * *}$ & $.511^{* * * *}$ & 1 & \\
\hline Depression & $.215^{*}$ & $.267^{* *}$ & -.061 & $.393^{* * * *}$ & $.502^{* * * *}$ & $.726^{* * *}$ & 1 \\
\hline
\end{tabular}

Notes: Higher scores on Parental Monitoring Scale indicate lower levels of parental monitoring. Higher scores on GPA indicate worse GPA. PIU was measures using the PIUQ, with higher PIUQ scores indicating higher level of PIU. Sleep quality, substance use, anxiety, and depressive symptoms were measured using the DSM-5 Cross-Cutting Assessment-Child, with higher scores indicating worsening symptoms.

$* p<.05, * * p<.01, * * * p<.001,{ }^{+} p<.10$ 
Table 2. Factor loadings of each measurement for the measurement model

\begin{tabular}{|c|c|c|c|}
\hline Problem Internet Use Questionnaire Items & $\begin{array}{l}\text { Factor 1: } \\
\text { Control disorder }\end{array}$ & $\begin{array}{l}\text { Factor 2: } \\
\text { Obsession }\end{array}$ & $\begin{array}{l}\text { Factor 3: } \\
\text { Neglect }\end{array}$ \\
\hline $\begin{array}{l}\text { 3. How often do you feel that you should decrease the amount of time spent on } \\
\text { line? }\end{array}$ & $.46^{* * *}$ & & \\
\hline $\begin{array}{l}\text { 6. How often does it happen to you that you wish to decrease the amount of time } \\
\text { spent online but you do not succeed? }\end{array}$ & $.72 * * *$ & & \\
\hline 9. How often do you try to conceal the amount of time spent online? & $.40 * * *$ & & \\
\hline 12. How often do you feel that your Internet usage causes problems for you? & $.62 * * *$ & & \\
\hline $\begin{array}{l}\text { 15. How often do you realize saying, when you are online, "just a couple of more } \\
\text { minutes and I will stop?" }\end{array}$ & $.79 * * *$ & & \\
\hline 1. How often do you fantasize about the Internet or think about what it would be & & $.73 * * *$ & \\
\hline like to be online when you are not on the Internet? & & & \\
\hline 4. How often do you daydream about the Internet? & & $.68 * * *$ & \\
\hline
\end{tabular}


7. How often do you feel tense, irritated, or stressed if you cannot use the Internet

for as long as you want to?

10. How often do you feel tense, irritated, or stressed if you cannot use the Internet

for several days?

13. How often does it happen to you that you feel depressed, moody, or nervous

when you are not on the Internet and these feelings stop one you are back online?

16. How often do you dream about the Internet?

$.67 * * *$

2. How often do you neglect household chores to spend more time online?

5. How often do you spend time online when you'd rather sleep?

11. How often does the use of the Internet impair your work or your efficacy?

14. How often do you lose sleep due to late-night log-ins?

1. Do your parents/guardians know what you do during your free time? 
2. Do your parents/guardians know who you have as friends and what do you do during your free time?

3. Do your parents/guardians usually know what type of homework you have?

4. Do your parents/guardians know what you spend your money on?

5. Do your parents/guardians usually know when you have an exam or paper due at school?

6. Do your parents/guardians know how you do in different subjects at school?

7. Do your parents/guardians know where you go when you are out with friends at night?

8. Do your parents/guardians normally know where you go and what you do after school?

DSM-Cross Cutting Assessment for substance use

1. How often have you been drinking at least 4 drinks of any kind of alcohol in a single day?
One factor

$.73^{* * *}$ 
2. How often have you been smoking any cigarette, a cigar, or pipe, or using snuff

or chewing tobacco?

3. How often have you been using any of the following medicine?

$.62 * * *$

DSM-Cross Cutting Assessment for anxiety

1. How often have you felt nervous, anxious, or scared?

2. How often have you been able to stop worrying?

3. How often have you not been able to do things you wanted to or should have done, because they made you feel nervous?
One factor

$.67 * * *$

$.90 * * *$

$.61 * * *$

DSM-Cross Cutting Assessment for depression

One factor

1. How often have you had less fun doing things than you used to?

$.49 * * *$

2. How often have you felt sad or depressed for several hours?

$.67 * * *$ 
Table 3. Structural model results $(N=247)$

\begin{tabular}{lc}
\hline Path & Standard coefficients ${ }^{\mathrm{a}}$ \\
\hline Direct effects on PIU & $-.08(.07)$ \\
Age & $.25(.07)^{* * *}$ \\
Gender & $.20(.10)^{+}$ \\
Non-Latinx Black & $.16(.10)$ \\
Latinx & $.27(.07)^{* * *}$ \\
Parental monitoring & \\
\hline Direct effects on academic achievement & $-.09(.07)$ \\
Age & $-.18(.06)^{* *}$ \\
Gender & $.01(.10)$ \\
Non-Latinx Black & $.05(.10)$ \\
Latinx & $.22(.07)^{* *}$ \\
Parental monitoring & $-.17(.08)^{*}$ \\
PIU &
\end{tabular}


Latinx

Parental monitoring

PIU

Direct effects on substance use

Age

Gender

Non-Latinx Black

Latinx

Parental monitoring

PIU

Direct effects on anxiety

Age

Gender

Non-Latinx Black

Latinx

Parental monitoring

PIU

Direct effects on depression

Age
$.02(.10)$

$.10(.07)$

$.26(.08)^{* *}$

$.05(.08)$

$-.14(.08)^{+}$

$.02(.16)$

$-.08(.11)$

$-.08(.09)$

$-.01(.09)$

$-.05(.07)$

$-.02(.08)$

.05 (.11)

$.06(.11)$

$.16(.08)^{+}$

$.01(.09)$

$.08(.09)$ 
Gender

Non-Latinx Black

Latinx

Parental monitoring

PIU
$.06(.09)$

$-.09(.14)$

$.02(.13)$

$.14(.10)$

$.24(.11)^{*}$

Notes: Higher scores on Parental Monitoring Scale indicate lower levels of parental monitoring. Higher scores on academic achievement indicate worse GPA. PIU was measures using the PIUQ, with higher PIUQ scores indicating higher level of PIU. Sleep quality, substance use, anxiety, and depressive symptoms were measured using the DSM-5 Cross-Cutting Assessment-Child, with higher scores indicating worsening symptoms.

a. For direct paths, standard path coefficients and standard errors were reported. Medication effects were examined using Bootstrap 1000, and 95\% CI of mediation effects of PIU were reported.

$* p<.05, * * p<.01, * * * p<.001,{ }^{+} p<.10$ 
Figure 1. PIU mediates the associations between parental monitoring and outcomes of academic achievement, sleep quality, substance use, anxiety, and depression.

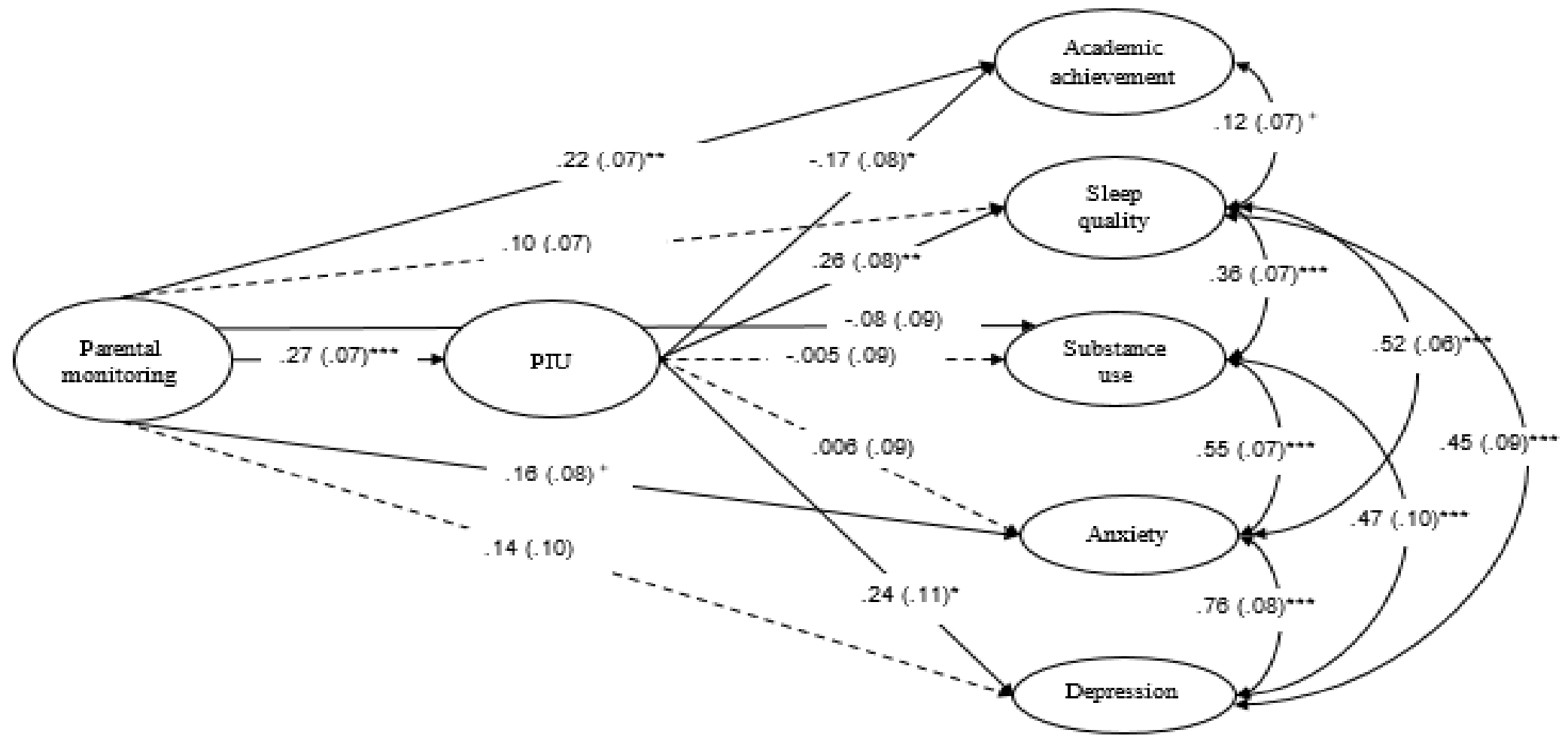

Note. Standardized path coefficients (standardized errors) were presented, $* p<.05 * * p<.01 * * * p<.001$. The effects of age, gender, and race/ethnicity (Non-Latinx Black vs. Latinx Black, Latinx vs. non-Latinx) on PIU, academic achievement, sleep quality substance use, anxiety, and depression were controlled for. Correlations among academic achievement, sleep quality substance use, anxiety, and depression were estimated. Only significant correlations among these endogenous variables were presented. 


\section{Tables and Figures for Manuscript 3}

Table 1. Measures Mean Scores and Standard Deviations (SD)

\begin{tabular}{lcc}
\hline Measure & $N$ & Mean (SD) \\
\hline Problematic Internet Use (PIU) & 147 & $4.00(1.71)$ \\
Problematic Video Gaming (PVG) & 154 & $3.49(1.42)$ \\
Family Household Composition & 159 & $1.73(0.84)$ \\
Acculturation & 52 & $3.67(1.91)$ \\
Parental Attachment & 131 & $5.48(1.79)$ \\
Future Orientation & 151 & $5.95(1.06)$
\end{tabular}

Note: PIU was measured using the PIUQ, with higher PIUQ scores indicating higher level of PIU. Parental attachment was measured using the IPPA, with higher scores indicating greater parental attachment. Acculturation was measured using the Stephenson Multigroup Acculturation Scale, with higher scores suggesting more acculturation. Future orientation was measured using the Adolescent Resilience Scale, with a higher score indicating greater future orientation. 
Table 2. Correlation Coefficients for All Variables

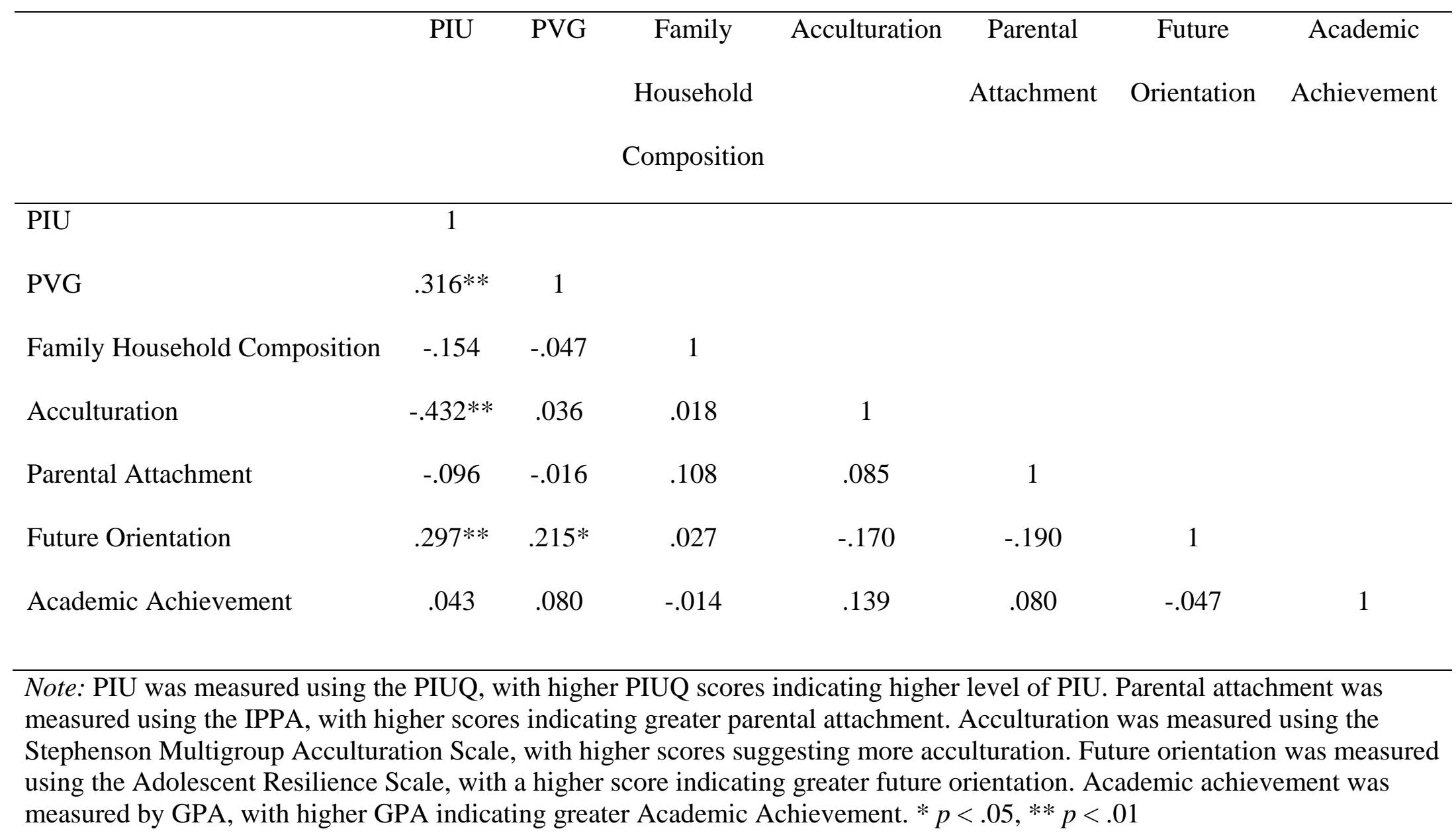


Figure 1. Model of PIU mediates the association between family household composition, parental attachment, acculturation, future orientation and academic achievement

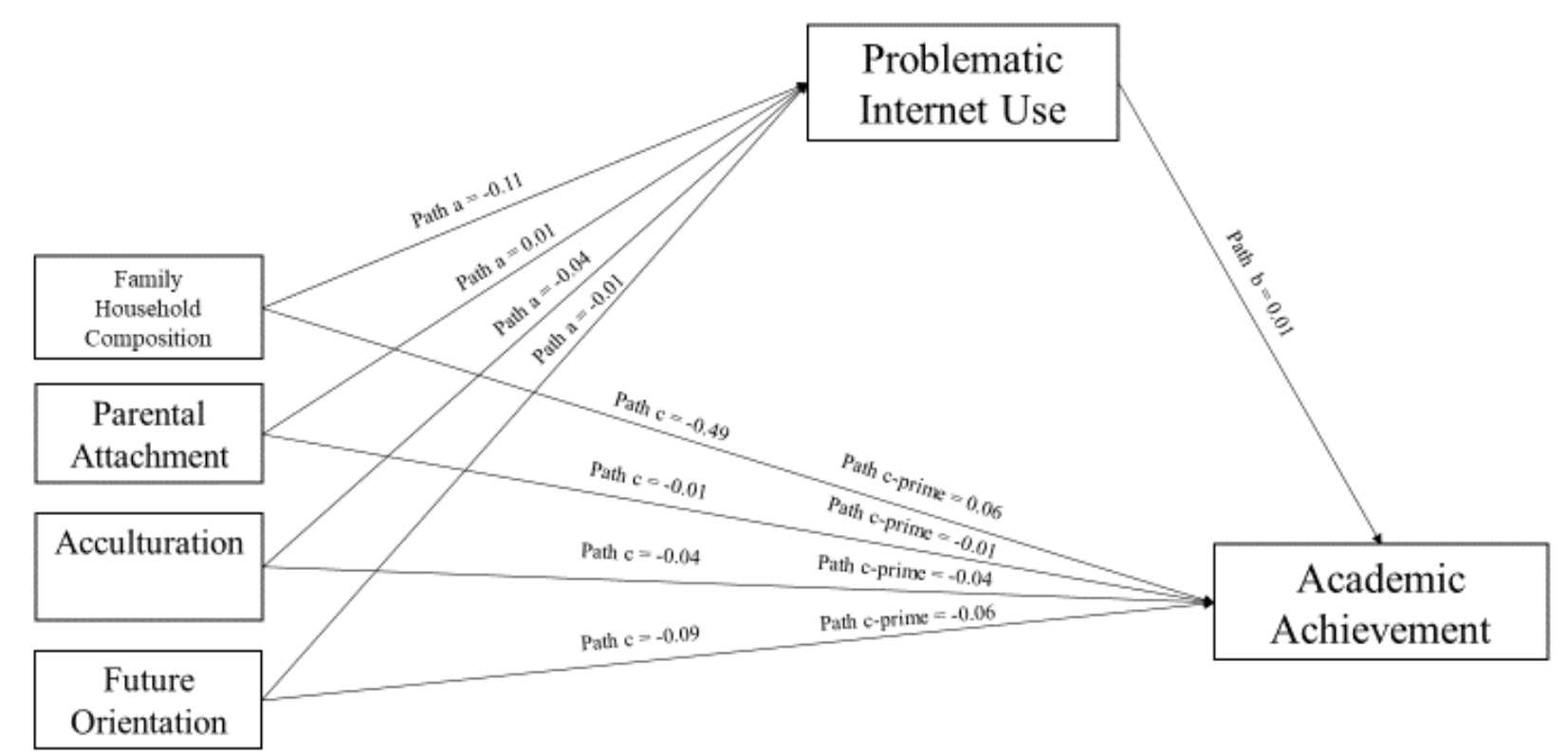

Note. Standardized path coefficients were presented, $* p<.05 * * p<.01 * * * p<.001$. Age and sex were controlled for. 
Figure 2. Model of PVG mediates the association between family household composition, parental attachment, acculturation, future orientation and academic achievement

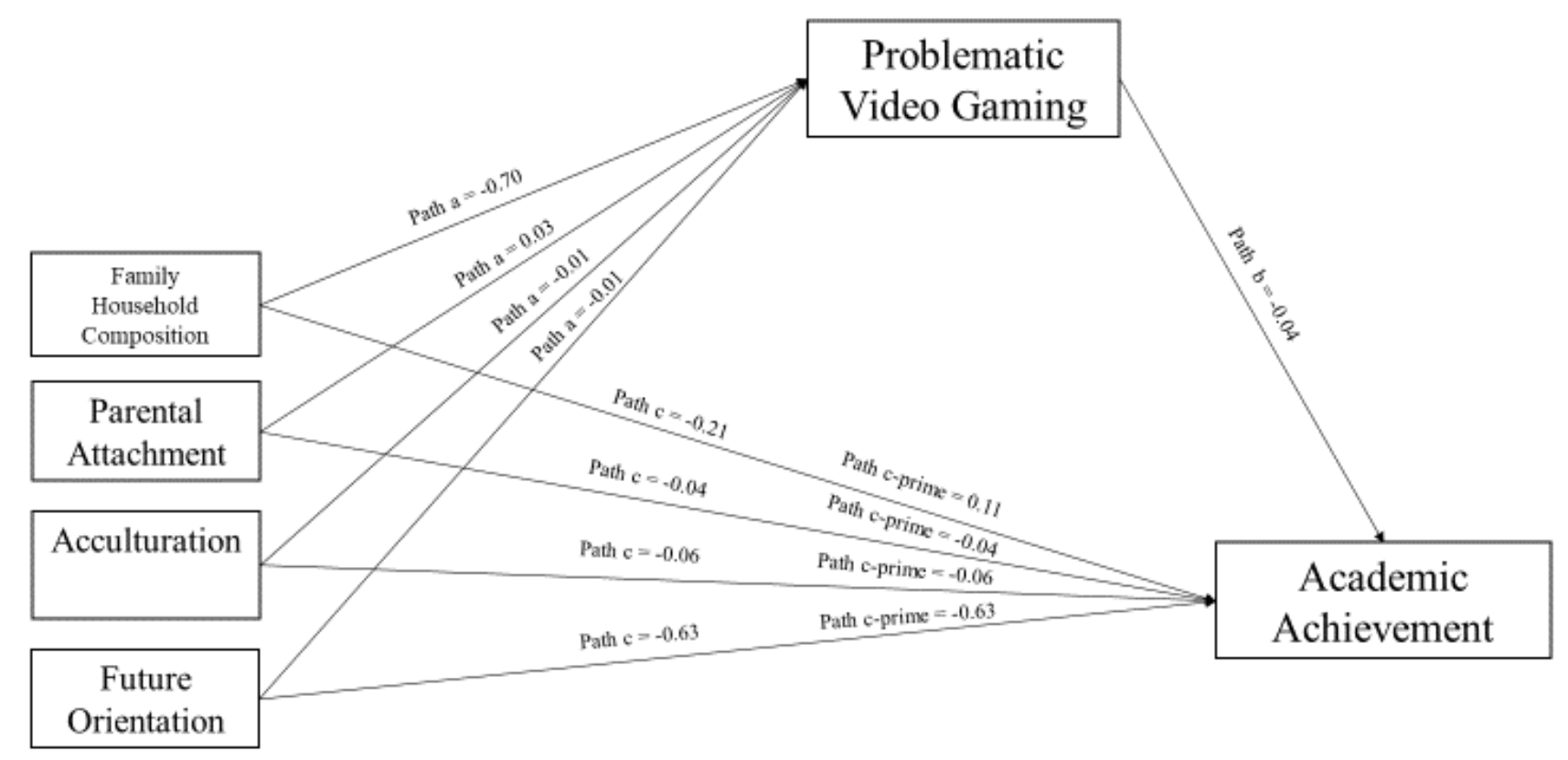

Note. Standardized path coefficients were presented, ${ }^{*} p<.05 * * p<.01 * * * p<.001$. Age and sex were controlled for. 
VITA

STEPHANIE L. DIEZ

Born, Miami, Florida

$2005-2009$

B.A., Psychology

Florida International University

Miami, Florida

$2011-2013$

M.S.W.

Florida International University

Miami, Florida

$2015-2018$

C-SALUD Student Scholar in Health Disparities Research

Fellow

Center for Research on US Latino HIV/AIDS and Drug

Abuse

Florida International University

Miami, Florida

$2018-2019$

Doctoral Candidate

Dissertation Year Fellow

Florida International University

Miami, Florida

\section{PUBLICATIONS AND PRESENTATIONS}

Kanamori, M., De La Rosa, M., Diez, S.L., Weissman, J., Trepka, M.J., Sneij, A.,

Schmidt, P., \& Rojas, P. (2017). Development, lessons learned, and preliminary findings

of Progresso En Salud, an HIV risk reduction intervention for Latina seasonal farmworkers, International Journal of Environmental Research and Public Health, 14 (32), 1-16.

Diez, S. L., Cristello, J. V., Dillon, F. R., De La Rosa, M., \& Trucco, E. M. (2019). Validation of the electronic cigarette attitudes survey (ECAS) for youth. Addictive Behaviors. 91, 216-221. 
Li, W., Diez, S. L., \& Zhao, Q. (In Press). Exploring Problematic Internet Use Among Non-Latinx Black and Latinx Youth Using the Problematic Internet Use QuestionnaireShort Form (PIUQ-SF). Psychiatry Research.

Diez, S.L., Anthony, V.L., and Elliott, L. (2018, January). DSM-5 Internet Gaming

Disorder in the U.S. Among Racial/Ethnic Minority Youth: Investigating Psychometric

Properties of the Internet Gaming Disorder Test and Psychosocial Correlates of Internet

Gaming Disorder Oral. Oral presentation to the Society for Social Work and Research

Conference, Washington, DC.

Anthony, V.L., Diez, S.L., and Zhao, Q. (2018, January). Problematic Internet Use Behaviors Among Racial/Ethnic Minority Youth in the United States: A Latent Class Analysis. Oral presentation to the Society for Social Work and Research Conference, Washington, DC.

Diez, S.L., and De La Rosa, M. (2017, March). The Effect of Parental Monitoring on U.S. Adolescents Frequency of Video Game Play. Oral presentation to the Latino Social Workers Organization Conference, Berkley, California.

Diez, S.L., Fava, N, \&, Mendel, W. (2017, March). Sexuality Education Web Sites and Social Media for Adolescents:An Untapped (unmeasured) Resource. Poster presented at the Annual Research and Policy Conference on Child, Adolescent \& Young Adult Behavioral Health, Tampa, FL.

Diez, S.L., and De La Rosa, M. (2016, April). Psychosocial interventions to treat Internet addiction and Internet Gaming Disorder among adolescents: A systematic review. Poster presented at the Latino Social Workers Organization Conference, New York, NY. 